\title{
Numerical Study on the Tandem Submerged Hydrofoils Using RANS Solver
}

\author{
Moloud Arian Maram $\left(\mathbb{D}\right.$, Hamid Reza Ghafari, Hassan Ghassemi $\mathbb{C D}^{\circ}$, and Mahmoud Ghiasi \\ Department of Maritime Engineering, Amirkabir University of Technology, 424 Hafez Ave. P.O. Box 15875-4413, Tehran, Iran \\ Correspondence should be addressed to Hassan Ghassemi; gasemi@aut.ac.ir
}

Received 16 August 2020; Revised 6 January 2021; Accepted 29 January 2021; Published 10 February 2021

Academic Editor: Luca Chiapponi

Copyright (c) 2021 Moloud Arian Maram et al. This is an open access article distributed under the Creative Commons Attribution License, which permits unrestricted use, distribution, and reproduction in any medium, provided the original work is properly cited.

\begin{abstract}
This paper is presented on the tandem two-dimensional hydrofoils with profiles NACA4412 in single-phase and two-phase flow domains for different submergence depths and different distances in a various angle of attack (AoA). Also, supercavitation is studied at $\sigma=0.34$ by the Zwart cavitation model. Reynolds-averaged Navier-Stokes (RANS) with the shear stress transport (SST) $K-\omega$ is employed as a turbulence model in transient analysis of Ansys FLUENT software. The numerical results show that, by increasing depth, the drag coefficient increases for both hydrofoils 1 and 2 as well as the lift coefficient. The drag coefficient of hydrofoil 2 is bigger than hydrofoil 1 for all depths; moreover, it was found that the flow pressure behind the hydrofoil 1 had affected the upper and the lower surface of the hydrofoil 2 at each distance or AoA. These effects are observed in the hydrofoil 2 lift coefficient as well as the flow separation. However, the maximum lift-to-drag ratio is observed at AoA $=8^{\circ}$ and $3.5 \mathrm{c}$ distance. Also, single-phase results reveal that the value of pressure and the hydrodynamic coefficient are very different from the two-phase flow results, due to the elimination of the free surface. So, a two-phase flow domain is recommended for increasing the accuracy of results. In addition, the investigation of supercavitation shows a growth in cavity occurrence on the surface by raising AoA.
\end{abstract}

\section{Introduction}

Tandem hydrofoils have been employed to create a lift force on the hull and make the boat rise out of the water, which lead to the reduction in the resistance force. This technology usually resulted in an increased lift-drag ratio and made it possible to achieve higher speeds. The hydrofoil is one of the important elements of the high-speed craft. There are different types of hydrofoil configurations that have been adopted in the marine industry such as in the passenger craft and pleasure yachts. Figure 1 shows an example of the passenger hydrofoil craft with the tandem hydrofoils.

Hydrodynamic performance has been attracted by the researchers for conducting a numerical simulation. This method has been used to analyze models in different situations and study the effect of various factors on the performance of the model. Reynolds-averaged Navier-Stokes (RANS) is the fundamental equation to simulate problems in the hydrodynamic field. Also, the choice of the correct turbulence model is an essential part of solving hydrodynamic problems. Sharma et al.
[1], Liu and Hekkenberg [2], Kandil and Elnady [3], and Mehdi et al. [4] studied the effect of AoA on some factors. They used the experimental method and numerical simulation for studying several foils with different profiles. It is evident from their results that an increase of AoA causes a rise of hydrodynamic force, wake, and separation. Besides, the lift force was increased by the increase of the Reynolds number. Also, the increase of AoA leads to reduce in lift force error and increase in drag force error. Also, Sharma et al. [1] conducted experimental and numerical simulations, in which experimental results confirmed the accuracy of $2 \mathrm{D}$ numerical simulation results.

Adjali et al. [5] investigated the accuracy of VOF and K-W (SST) for generating the wave. Results demonstrated that these models are suitable for modeling the wave. Shahariar [6] added a flap with a length of $4 \%$ the camber on the upper surface of a foil, near the leading edge. Results indicated cavitation on the surface was controlled by the flap, so the lift coefficient and stall angle have been enhanced. Investigation of cavitation on multielement foils was carried out by Udaya Kumar and Kannan [7]. The results of this study indicated multibody which 


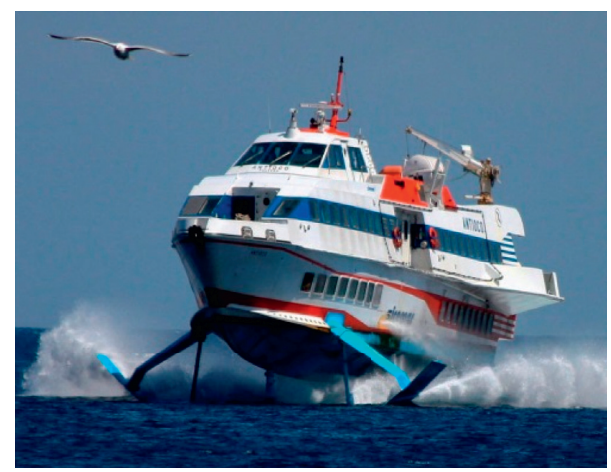

Figure 1: Passenger hydrofoil craft.

led to deferring to induce cavitation. The effect of foil thickness was researched by Sogukpinar [8] in which this parameter led to reduced lift coefficient. Esmaeilifar et al. and Uddin and Karim [9] conducted a 2D simulation to analyze submergence depth. Esmaeilifar et al. also studied the effect of oscillation frequency. At $h / c=0.5 c$, the lift force increases at all frequencies. At other depths, the force increase occurs only at the critical frequency. Wave amplitude was reduced by increasing submergence depth. Additionally, an increase in submergence depth increases lift coefficients and reduces drag coefficients.

Previous investigations have been carried out to investigate the effect of AoA, velocity, and difference between kinds of foils and other basic factors. Therefore, this paper has investigated the effect of foils on each other. Also, the objective of this paper is to study the effect of submergence depths, different distances in the various angle of attack (AoA) on the lift, and drag coefficients of the tandem hydrofoils with NACA4412 profiles in a two-phase flow computational domain. The dimensionless free surface shape on the tandem hydrofoils for different case studies is presented and discussed. The numerical simulations of the submerged tandem hydrofoils are carried out using the volume of fluid (VOF) method in Ansys FLUENT's transient solver. Furthermore, this paper studies supercavitation at $\sigma=0.34$ and its growth on the surface by changing AoA.

\section{Governing Equations}

The turbulent flow around the hydrofoil is calculated in the case of a two-dimensional incompressible Reynolds-averaged Navier-Stokes equations (RANS) using the finite volume method (FVM). Continuity and momentum equations can be written as

$$
\begin{gathered}
\frac{\partial u}{\partial x}+\frac{\partial v}{\partial y}=0 \\
\frac{\partial u}{\partial t}+u \frac{\partial u}{\partial x}+v \frac{\partial u}{\partial y}=-\frac{1}{\rho} \frac{\partial p}{\partial x}+v\left(\frac{\partial^{2} u}{\partial x^{2}}+\frac{\partial^{2} u}{\partial y^{2}}\right) \\
\frac{\partial v}{\partial t}+u \frac{\partial v}{\partial x}+v \frac{\partial v}{\partial y}=g-\frac{1}{\rho} \frac{\partial p}{\partial y}+v\left(\frac{\partial^{2} v}{\partial x^{2}}+\frac{\partial^{2} v}{\partial y^{2}}\right)
\end{gathered}
$$

where $u$ and $v$ are the $x$-component and $y$-component of the velocity vector. To define the turbulence closure, the shearstress transport (SST) $k-\omega$ model was adopted in the FLUENT commercial code. The $k-\omega$ SST model embraces the best of the two turbulent models developed by Menter and Rumsey [10]: the $k-\varepsilon$ in the free-stream region and the $k-\omega$ at the near-wall in the boundary layer.

The compressible equations of kinetic turbulent energy and specific dissipation rate conservation can be written as equations (2) and (3):

$$
\begin{aligned}
& \frac{\partial(\rho k)}{\partial t}+\frac{\partial\left(\rho U_{i} k\right)}{\partial x_{i}}=\widetilde{P}_{k}+\beta^{*} \rho k \omega+\frac{\partial}{\partial x_{i}}\left[\left(\mu+\sigma_{k} \mu_{t}\right) \frac{\partial k}{\partial x_{i}}\right] \\
& \frac{\partial(\rho \omega)}{\partial t}+\frac{\partial\left(\rho U_{i} \omega\right)}{\partial x_{i}}=\alpha \rho S^{2}+\beta \rho \omega^{2}+\frac{\partial}{\partial x_{i}}\left[\left(\mu+\sigma_{k} \mu_{t}\right) \frac{\partial \omega}{\partial x_{i}}\right] \\
& \quad+2\left(1-F_{1}\right) \rho \sigma_{\omega 2} \frac{1}{\omega} \frac{\partial k}{\partial x_{i}} \frac{\partial \omega}{\partial x_{i}},
\end{aligned}
$$

where $F_{1}$ represents the blending function which can be obtained as

$$
F_{1}=\tanh \left\{\left\{\min \left[\max \left(\frac{\sqrt{k}}{\beta^{*} \omega y}, \frac{500 v}{y^{2} \omega}\right), \frac{4 \rho \sigma_{\omega 2} k}{\mathrm{CD}_{k \omega} y^{2}}\right]\right\}^{4}\right\},
$$

where

$$
\mathrm{CD}_{k \omega}=\max \left(2 \rho \sigma_{\omega 2} \frac{1}{\omega} \frac{\partial k}{\partial x_{i}} \frac{\partial \omega}{\partial x_{i}}, 10^{-10}\right),
$$

where $y$ is the distance to the nearest wall and $v$ is the kinematic viscosity. In the shear-stress transport (SST) model, $F_{1}$ is equal to zero for far field in the $k-\varepsilon$ model and considers 1 for inside the boundary layer for the $k-\omega$ model.

Using a limited to the eddy viscosity formulation, the proper transport behavior can be achieved as follows:

$$
v_{t}=\frac{a_{1} k}{\max \left(a_{1} \omega, \mathrm{SF}_{2}\right)},
$$


where $F_{2}$ is a second blending function, which restricts the limiter to the wall boundary layer, and $S$ is the invariant measure of the strain rate. $F_{2}$ is defined as

$$
F_{2}=\tan h\left[\left[\max \left(\frac{2 \sqrt{k}}{\beta^{*} \omega y}, \frac{500 v}{y^{2} \omega}\right)\right]^{2}\right]
$$

In stagnation regions of the SST model, a production limiter is used to avoid the build-up of turbulence:

$$
P_{k}=\mu_{t} \frac{\partial U_{i}}{\partial x_{j}}\left(\frac{\partial U_{i}}{\partial x_{j}}+\frac{\partial U_{j}}{\partial x_{i}}\right) \longrightarrow \widetilde{P}_{k}=\min \left(P_{k}, 10 \beta^{*} \rho k \omega\right)
$$

All constant coefficient in the $k-\varepsilon$ turbulence model and the $k-\omega$ turbulence model is solved by $\alpha=\alpha_{1} F+\alpha_{2}(1-F)$, where $\alpha_{1}$ and $\alpha_{2}$ are constant coefficients in the $k-\omega$ and the $k-\varepsilon$ model equation. Table 1 shows the constants for this model.

To simulate two-phase flow, the volume-of fluid (VOF) method is used and the treatment for the free-surface flow uses an interface capturing method between water and air with the VOF and solving its scalar transition equation. Thus, for each moment and element, the volume fraction ratio of each fluid phase can be written as follows [11]:

$$
\frac{\partial F}{\partial t}+u \frac{\partial F}{\partial x}+v \frac{\partial F}{\partial y}=0
$$

$F=1$ and 0 denote the cell is full of water and air, respectively. Furthermore, when $0<F<1$, free surface is formed and the cells are filled with a mixture of water air phases.

The interaction between the hydrofoil and fluid results in two main forces, which are commonly given by the drag and lift coefficients:

$$
\begin{aligned}
& C_{d}=\frac{F_{x}}{0.5 \rho U_{\infty}^{2} C}, \\
& C_{L}=\frac{F_{y}}{0.5 \rho U_{\infty}^{2} C},
\end{aligned}
$$

where $F_{x}$ and $F_{y}$ are the drag and lift forces, respectively, $\rho$ is the density, $U_{\infty}$ is the upstream velocity, and $C$ is the hydrofoil chord.

The pressure coefficient distribution on the hydrofoil can be written as

$$
C_{\text {Press }}=\frac{P-P_{\text {ref }}}{0.5 \rho U_{\infty}^{2}}
$$

where $P$ is the local pressure, $P_{\text {ref }}$ is the reference hydrostatic pressures, and $U_{\infty}$ and $\rho$ are the free-stream velocity and fluid density, respectively.

Moreover, the cavitation number is calculated by

$$
\sigma=\frac{P-P_{v}}{0.5 \rho U_{\infty}^{2}}
$$

where $P_{v}$ is that the vapor pressure which is $3169 \mathrm{~Pa}$.
TABle 1: Constants' coefficients.

\begin{tabular}{lccc}
\hline$\alpha_{1}$ & $5 / 9$ & $\beta_{1}$ & $3 / 40$ \\
\hline$\alpha_{2}$ & 0.44 & $\beta_{2}$ & 0.0828 \\
$\sigma_{k 1}$ & 0.85 & $\sigma_{k 2}$ & 1 \\
$\sigma_{\omega 1}$ & 0.5 & $\sigma_{\omega 2}$ & $1 / .0856$ \\
$\beta^{*}$ & 0.09 & & \\
\hline
\end{tabular}

\section{Numerical Setup and Mesh Study}

3.1. Computational Domain and Boundary Conditions. The hydrofoil domain size reported by several researchers may be different from each other. In this paper, to prevent the reflection of waves at the outlet and the formation of surface waves, the computational domain in the upstream and downstream should be large enough. Dimensions of the domain expressed in the nondimensional form as inlet and outlet are located at $4 c$ upstream and $8 c$ downstream in the fluid direction, respectively, where $c$ is the hydrofoil chord and the domain extends $3 c$ for the top and bottom location. $\alpha$ was defined as the angle of attack (AoA), $d$ is the distance between hydrofoil 1 and 2, and $h$ is hydrofoil's depth and was considered to be equal to $0.8 c$. The dimensions of the model are presented in Figure 2.

As shown in Figure 2, the uniform incoming velocity is considered for the inlet boundary condition, while a constant pressure was applied at the outlet and top boundary condition. For the hydrofoil 1 and 2 surfaces and bottom boundary, a no-slip wall condition has been used. The numerical settings are presented in Table 2.

To create a suitable mesh for the two-dimensional domain, the domain is divided into three parts in the Ansys meshing program, and then, the surface sizing mesh has been used to control the element size so that finer mesh is required near a hydrofoil. Figure 3 reveals mesh on the whole picture of domain, a close picture of the hydrofoil, and the boundary layer. The average cell size in the coarse regions is $0.1 \mathrm{~m}$, in the medium region is $0.03 \mathrm{~m}$, and in the refined region is $0.01 \mathrm{~m}$.

A 2D hydrofoil had been chosen with profile NACA4412 and chord length $(c) 1 \mathrm{~m}$ to validate the next simulations. The hydrofoil has been fixed horizontally in the domain. To investigate the effect of elements' number on the lift coefficient in the two-dimensional simulation, the number of the required elements has been changed several times, and the numerical results obtained from Ansys FLUENT commercial code is compared with experimental data reported by Wadcock [12] for $\mathrm{AoA}=10^{\circ}$ and $\mathrm{Re}=1.67 e+06$ in Figure 4.

For a quick convergence and the reduction in the computational time in the desired hydrofoil simulation, approximately 110 thousand elements are used. As shown in Figure 4, by increasing the elements' number more than 110 thousand elements, a significant change for the lift coefficient is not observed, and this increase can only lead to solution time increment.

3.2. Validation. To demonstrate the validity of the results, the present numerical results were compared with experimental data derived from the tests for the NACA 4412 pressure coefficient at $\mathrm{AoA}=8^{\circ}, 10^{\circ}$, and $12^{\circ}$ and $\operatorname{Re}=1.67 e+$ 06 in Figure 5. 


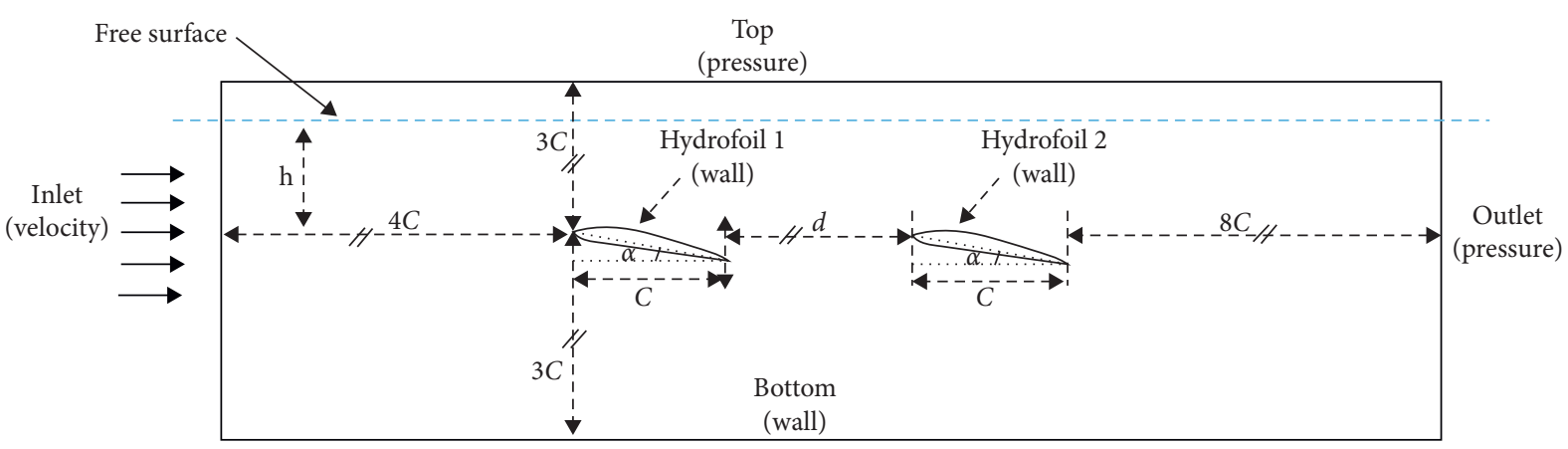

Figure 2: Dimensions of the domain and boundary condition.

TABle 2: Numerical setting.

\begin{tabular}{lc}
\hline Parameter & Setting \\
\hline Analysis type & Transient \\
Material & Water and air at ${ }^{\circ} \mathrm{C}$ \\
Turbulence model & $K-\omega(\mathrm{SST})$ \\
Wall & No slip \\
Inlet & Normal speed \\
Outlet & Normal pressure \\
\hline
\end{tabular}

Figure 5 indicates that the numerical results obtained from the present computational procedure (for NACA 4412 pressure coefficients at three angles of attack and $\operatorname{Re}=1.67 e+06)$ agree well with the experimental data reported by Wadcock [12]. Table 3 shows a value of $C_{L}$ and $C_{d}$ for numerical and experimental methods and errors of two methods at three angles of attack changing from ${ }^{8^{\circ}}$ to $12^{\circ}$ and the Reynolds number of $1.67 e+06$.

According to the error values presented in Table 3, the maximum error value for $C_{d}$ occurred at $\mathrm{AoA}=12^{\circ}$ and is acceptable for this method.

Moreover, for another validation, wave height had been compared with experimental results reported by Duncan [13]. This numerical simulation has been performed at $\mathrm{AoA}=5^{\circ}$, depth $=0.91$, Froude number $=0.5711$, and Reynolds number $1.592 e+05$, and model's chord length has been $203 \mathrm{~mm}$.

Comparing the result of wave elevations between the present method and the experimental in Figure 6 confirmed the accuracy of the present method.

The nondimensionalized wall distance $\left(y^{+}\right)$is one of the important parameters in the turbulent model, which is a nondimensional distance and is often used to describe the coarse or fine grid size for a particular flow pattern. It is important to determine the appropriate size of cells near the domain walls in a turbulent flow. The range of values for this parameter is different based on the type of turbulent model. $y^{+}$of the hydrofoil for the present computational procedure was in the range of $y+<1$ which is acceptable for the $k-\omega$ SST turbulence model. The wall distance is calculated with equations (13) and (14):

$$
\begin{aligned}
& y^{+}=\frac{\Delta y_{p} \times u^{*}}{v}, \\
& u^{*}=\sqrt{\frac{\tau_{w}}{\rho}},
\end{aligned}
$$

where $\Delta y_{p}, u^{*}, v, \tau_{w}$, and $\rho$ are the thickness of the first layer (the closest layer to a wall), the velocity of friction in the first layer, kinematic viscosity of flow, wall shear stress, and density of flow, respectively. In this investigation, the value of the wall distance is less than one.

\section{Results and Discussion}

To investigate the effect of submergence depths on the lift and drag coefficients, NACA 4412 sectional geometry with AoA $=10^{\circ}$ is considered as the tandem hydrofoil in the twophase flow domain. The chord length is $100 \mathrm{~cm}$ and the hydrofoil depth is equal to $0.8 c$. It should be noticed that all simulations have been carried out at $\mathrm{V}=25 \mathrm{~m} / \mathrm{s}$. Dynamic pressure and velocity magnitude obtained from Ansys FLUENT using $k$ - $\omega$ SST turbulence models are shown in Figure 7.

4.1. Investigation of Different Depths. Simulations are carried out for five different submergence depths. The tandem hydrofoils distance and AoA for both hydrofoils 1 and 2 are considered $3.5 \mathrm{c}$ and $10^{\circ}$, respectively. Furthermore, the flow velocity is $25 \mathrm{~m} / \mathrm{s}$ in all case studies. Dimensionless free surface shape on the tandem hydrofoils for 4 different submergence depths is presented in Figure 8. According to Figure 8, when the depth of the hydrofoil increases, it generates a smaller wave amplitude. It should be considered that the free surface obtained from volume fraction equal to 0.5 .

Figure 9 shows the results of simulation hydrofoil in different submergence depths which are changed based on $0.2 c$ step; from $0.6 c$ to $1.2 c$, furthermore, to compare better the result of simulation for the case of without free surface (W/O FSE) is shown.

Figure 9 indicates that the drag coefficient is increased for both hydrofoils 1 and 2 as well as the lift coefficient by increasing depth. Generally, the drag coefficient of hydrofoil 2 is bigger than hydrofoil 1 for all depths. Moreover, the difference between the lift coefficient for hydrofoils 1 and 2 is smaller than the drag coefficient. Moreover, $C_{L}$ for hydrofoil 1 is bigger than hydrofoil 2 , while $C_{d}$ is vice versa. Moreover, in the case of W/O FSE, $C_{d}$ of hydrofoil 2 decreases while hydrofoil $1 C_{d}$ increases. 


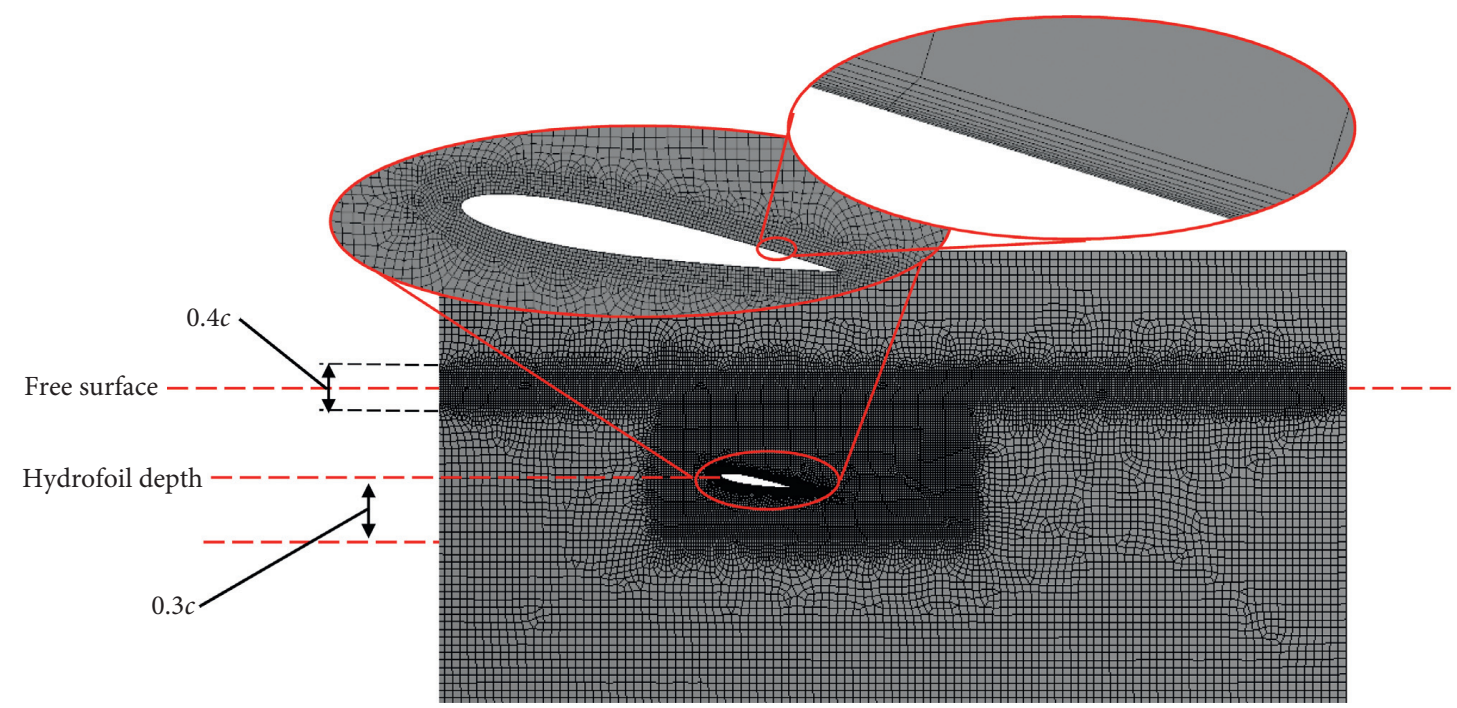

Figure 3: Mesh detail showing the hydrofoil and the free surface areas.

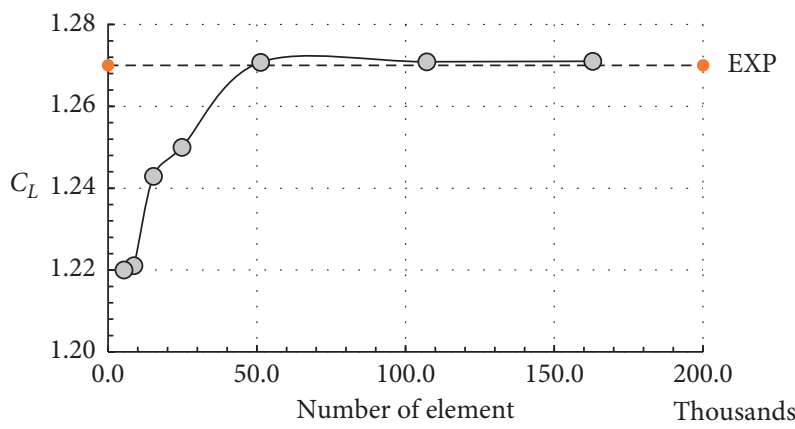

FIGURE 4: Lift coefficient variation at an increasing number of elements.

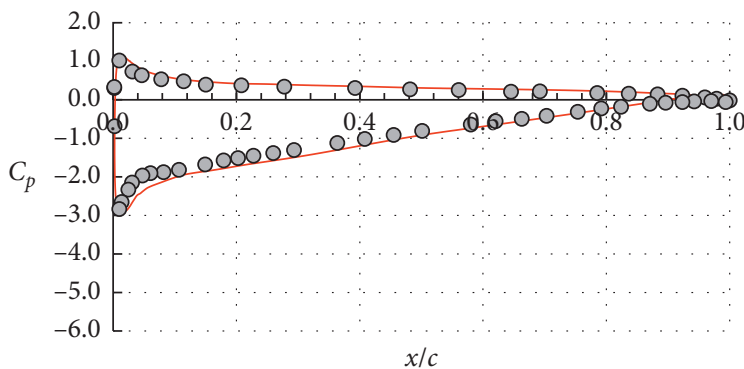

- Numerical, FLUENT

○ Experimental,...

(a)

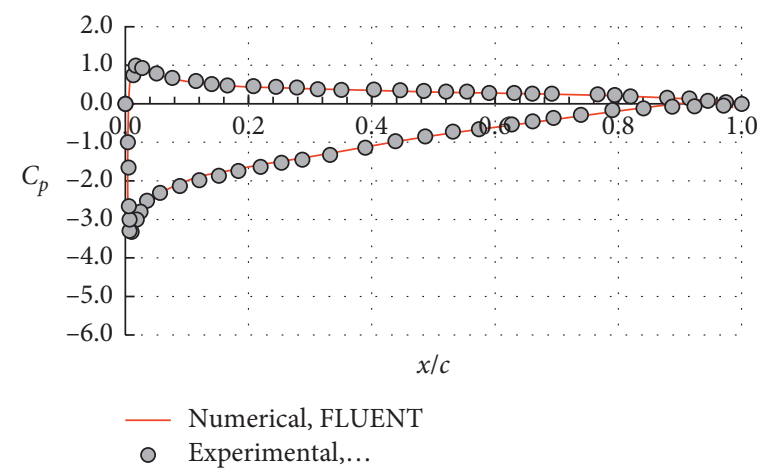

(b)

Figure 5: Continued. 


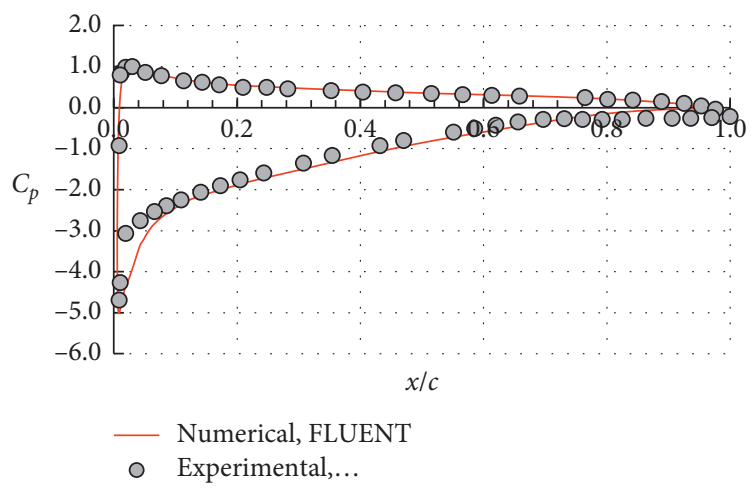

(c)

FIGURE 5: Comparison of pressure coefficients between numerical results and experimental data [12] (NACA 4412 and Re $=1.67 e+06)$. (a) $\mathrm{AoA}=8^{\circ}$. (b) $\mathrm{AoA}=10^{\circ}$. (c) $\mathrm{AoA}=12^{\circ}$.

TABle 3: Comparison of $C_{L}$ and $C_{d}$ between numerical results and experimental data.

\begin{tabular}{lcccccc}
\hline AoA $(\mathrm{deg})$ & $\left(C_{L}\right)_{\text {numerical }}$ & $\left(C_{L}\right)_{\text {experimental }}$ & \% error $\left(C_{L}\right)$ & $\left(C_{d}\right)_{\text {numerical }}$ & $\left(C_{d}\right)_{\text {experimental }}$ & $\%$ error $\left(C_{d}\right)$ \\
\hline 8 & 1.17 & 1.16 & 0.86 & 0.017 & 0.018 & -5.5 \\
10 & 1.22 & 1.28 & -4.6 & 0.023 & 0.024 & -4.1 \\
12 & 1.41 & 1.36 & 3.6 & 0.039 & 0.043 & -9.3 \\
\hline
\end{tabular}
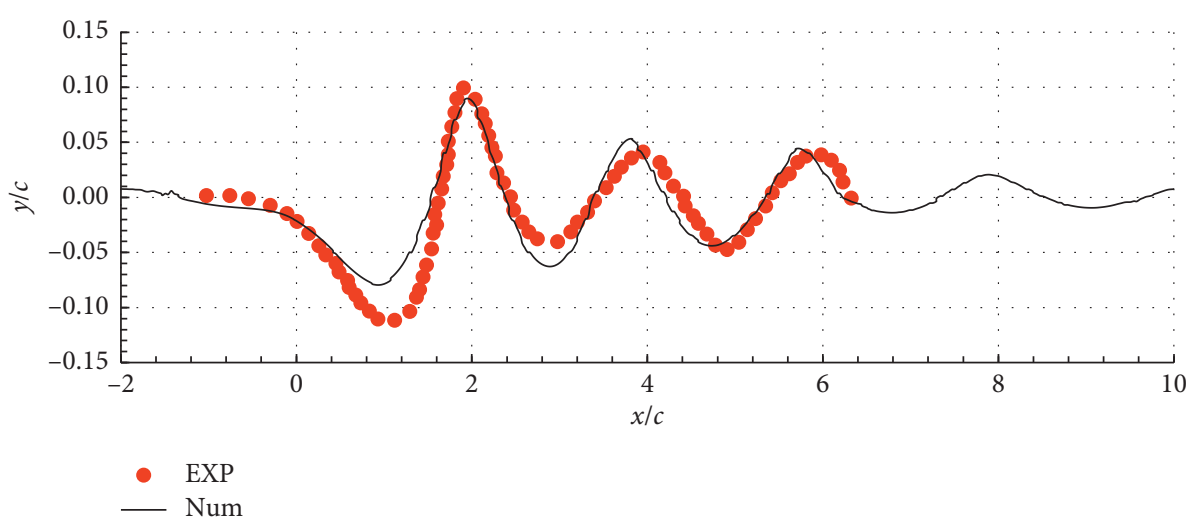

FIgURE 6: Comparison wave elevations between numerical results and experimental data[13] (NACA 0012 and $\operatorname{Re}=1.592 e+05)$.

Dynamic pressure

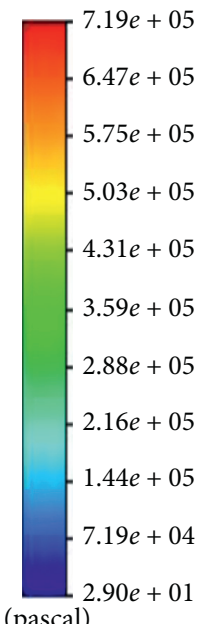

Velocity magnitude
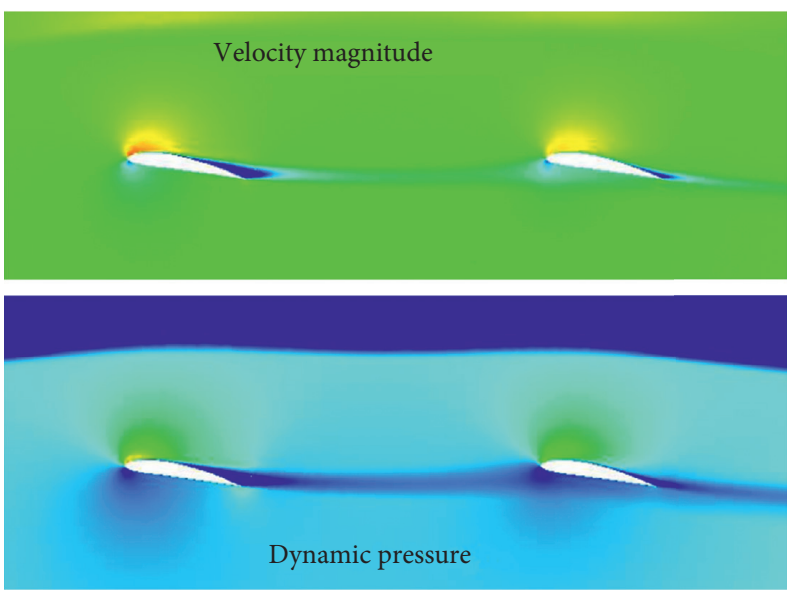

Dynamic pressure

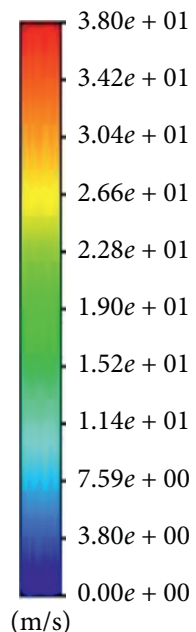

Figure 7: The contour of pressure and velocity on the tandem hydrofoils $\left(d=3.5 \mathrm{c}\right.$ and AoA $\left.=10^{\circ}\right)$. 


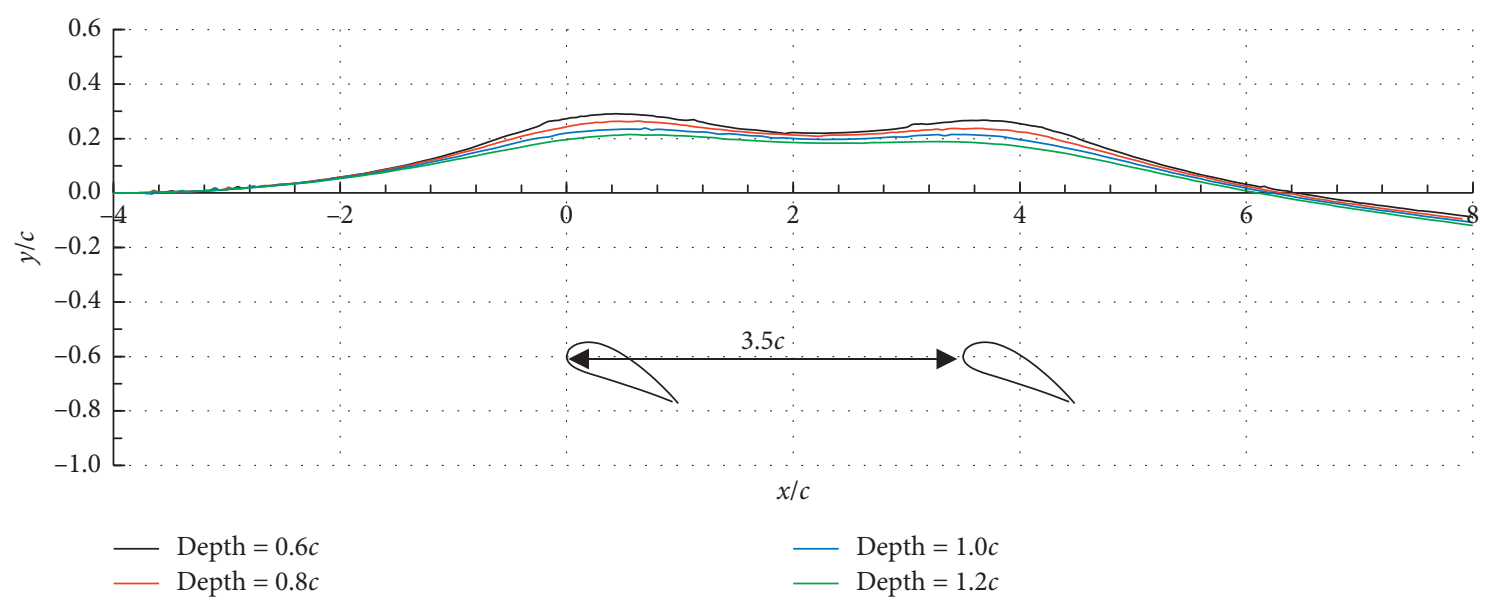

Figure 8: Free surface shape dimensionless on the tandem hydrofoils, for different depths $\left(d=3.5 c\right.$ and $\left.A o A=10^{\circ}\right)$.

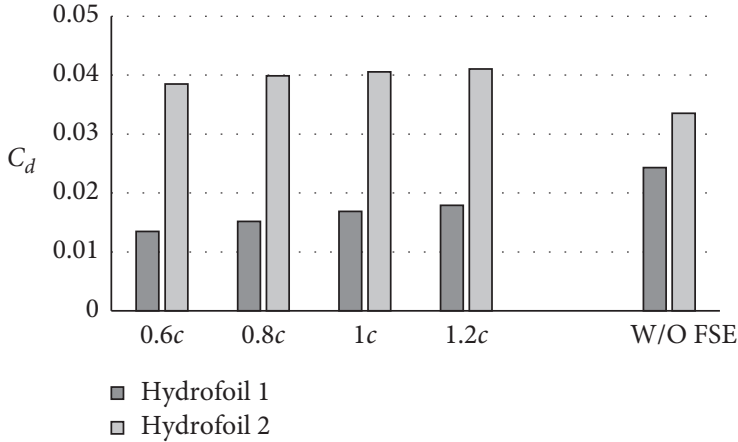

(a)

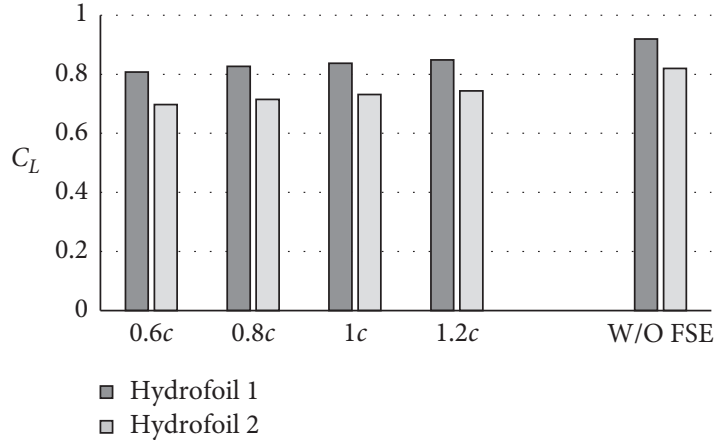

(b)

Figure 9: Lift and drag coefficients versus depth and W/O FSE $\left(d=3.5 \mathrm{c}\right.$ and AoA $\left.=10^{\circ}\right)$.

4.2. Investigation of Different Distances and AoAs. To observe the effect of the tandem hydrofoils distance on the hydrodynamics responses of NACA 4412, three case studies are investigated. Each case study includes 5 different AoAs from $8^{\circ}$ to $16^{\circ}$. The dimensionless free surface shape on the tandem hydrofoils for different distances and various AoA are presented in Figure 10, and submergence depth is $0.8 c$.

It can be seen from Figure 10 that increasing the AoA leads to an increase in the free surface height on both hydrofoil 1 and 2, while in downstream, the free surface height decreases.

As shown in Figure 11, increasing distances lead to variation in the free-surface profile, so in the case of $3.5 c$, the height of the free surface is smaller than that of $2.5 c$; also, it is clear that the distance of the second peak increased from the first peak.

Figure 12 shows the effects of AoA in $2.5 \mathrm{c}$ distance between the tandem hydrofoils on the lift and drag coefficients at two conditions: (a) depth is $0.8 c$ and (b) W/O FSE.

As shown in part (a) of Figure 12, the value of drag coefficient applied to the hydrofoil 1 has an upward trend, while maximum $C_{d}(0.072)$ of hydrofoil 2 occurs in $\mathrm{AoA}=14^{\circ}$ and after that decreases to 0.06 in $\mathrm{AoA}=16^{\circ}$. The lift coefficient of hydrofoil 2 for AoA from ${ }^{8^{\circ}}$ to $12^{\circ}$ have an uptrend and then demonstrate a downtrend for $12^{\circ}$ to $16^{\circ}$. In the case of hydrofoil 2, its trend is vice versa. Also, the maximum $C_{L}$ of hydrofoil 2 occurs in the case of $12^{\circ}$ and is the same value (nearly 0.7 ) as the minimum $C_{L}$ of hydrofoill. Also, comparing parts (a) and (b) shows that the elimination of free surface leads to an increase $C_{d}$ of hydrofoil 2. Besides, the maximum $C_{L}$ of hydrofoil 2 at depth $0.8 \mathrm{c}$ and W/O FSE occurs in the case of $12^{\circ}$. The effects of AoA on lift and drag coefficients at $3 c$ distance between the tandem hydrofoils at depth $=0.8 c$ and W/O FSE have been shown in Figure 13.

It was found in Figure 13 that increasing AoA lead to a sharp increase of drag coefficient for hydrofoil 1 , while $C_{d}$ for hydrofoil 2 increases gradually, and at $14^{\circ}$ and $16^{\circ}, C_{d}$ for hydrofoil 2 is approximately equal. As shown in Figure 11, taking into account the effect of the free surface, at AoA $=14^{\circ}$, the values of $C_{d}$ for both hydrofoils are equal to each other, while in the case of without free surface effect, $C_{d}$ at $\mathrm{AoA}=12^{\circ}$ is equal.

$C_{L}$ of hydrofoil 2 for AoA from ${ }^{8^{\circ}}$ to $14^{\circ}$ have an uptrend and then demonstrate downtrends from $14^{\circ}$ to $16^{\circ}$. In the case of hydrofoil 1, its trend is vice versa. Generally, both the maximum $C_{L}$ of hydrofoil $2(0.87)$ and minimum $C_{L}$ of hydrofoil 1(0.65) occur at AoA $=14^{\circ}$. Although, $C_{L}$ of both hydrofoils increases in the case of W/O FSE, the trend of 


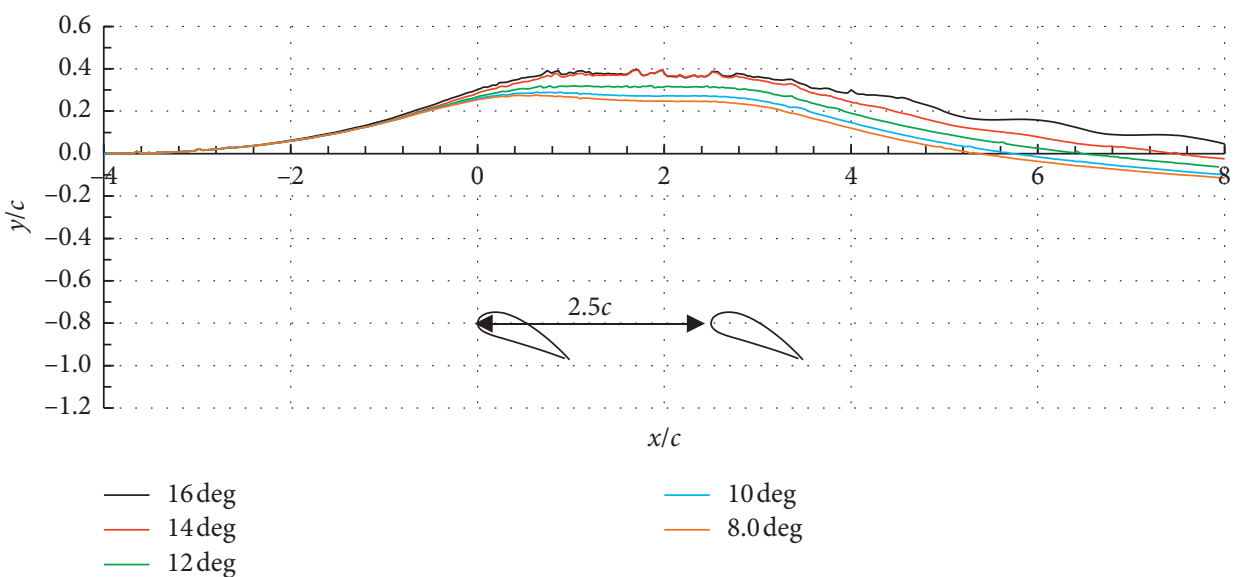

(a)

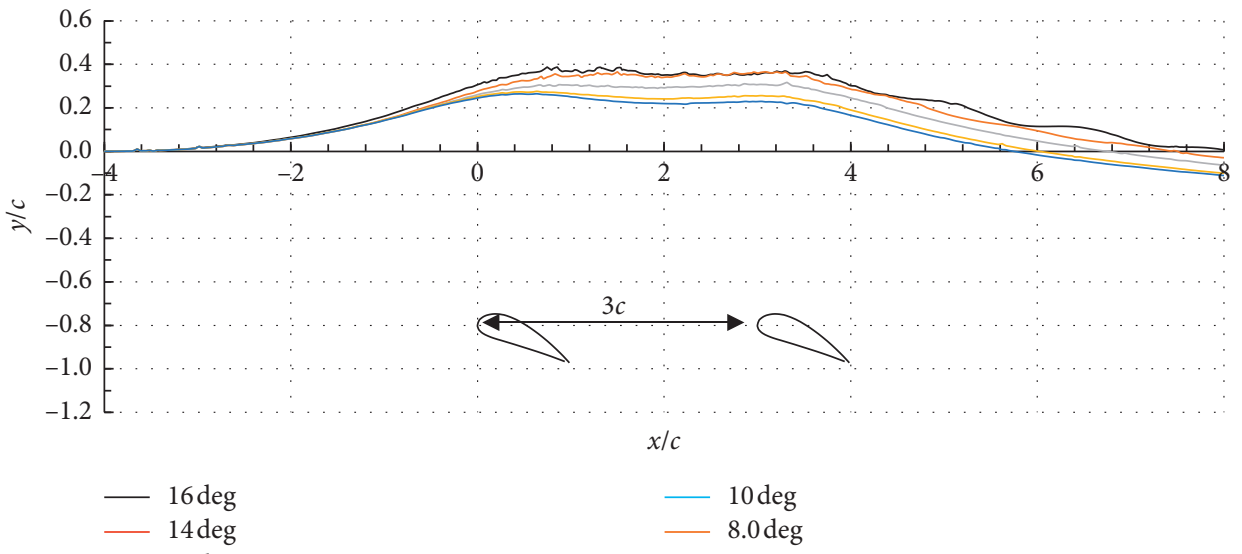

(b)

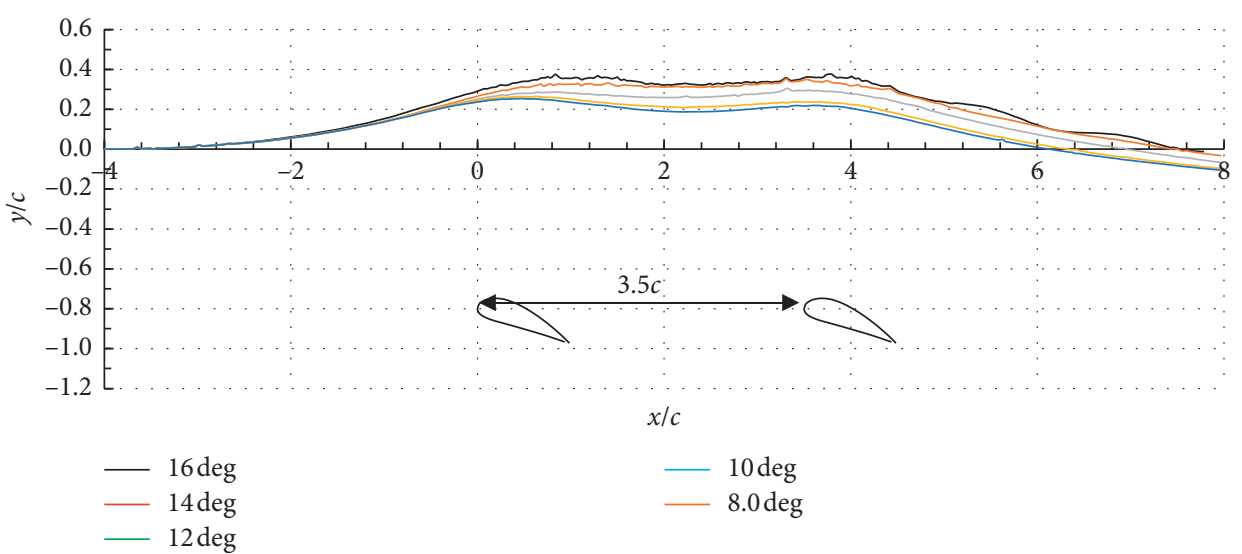

(c)

Figure 10: Dimensionless free surface shape for different distances and AoA (depth $=0.8 c$ ).

changes is alike. The effects of AoA on lift and drag coefficients in $3 c$ distance between the tandem hydrofoils have been revealed at depth $=0.8 c$ and W/O FSE in Figure 13 . Figure 14 demonstrates the effect of changing AoA from ${ }^{8^{\circ}}$ to $16^{\circ}$ at distance $3.5 \mathrm{c}$ on hydrodynamic coefficients at depth $=0.8 c$ and W/O FSE.

Figure 14 shows the drag coefficient in the case of $3.5 c$ which has similar trend in comparison with $2.5 c$ and $3 c$ distance, so increasing AoA leads to rise in $C_{d}$ for both hydrofoils, but it can be seen that hydrofoil 1 has a greater slope than hydrofoil 2 in all three case studies. The maximum lift coefficient of hydrofoil $2(0.8)$ belongs to $12^{\circ}$ and $14^{\circ}$, while for hydrofoil 1 , maximum $C_{L}$ occurs at ${ }^{8^{\circ}}$ AoA and equal to 0.82 , and after that, $C_{L}$ decreases to the minimum value (0.65) in $\mathrm{AoA}=14^{\circ}$. Also, the free surface leads to the maximum of $C_{L}$ at a smaller AoA for the hydrofoil 1 . 


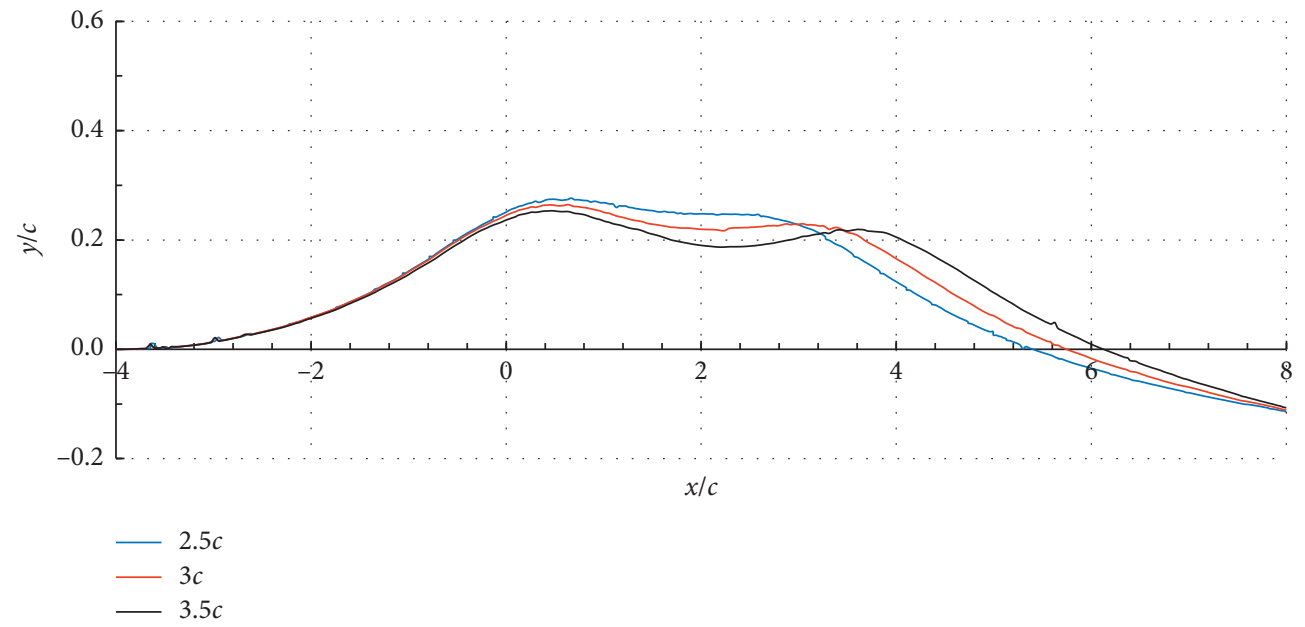

Figure 11: Dimensionless free surface shape for different distances: AoA $=8^{\circ}($ depth $=0.8 c)$.
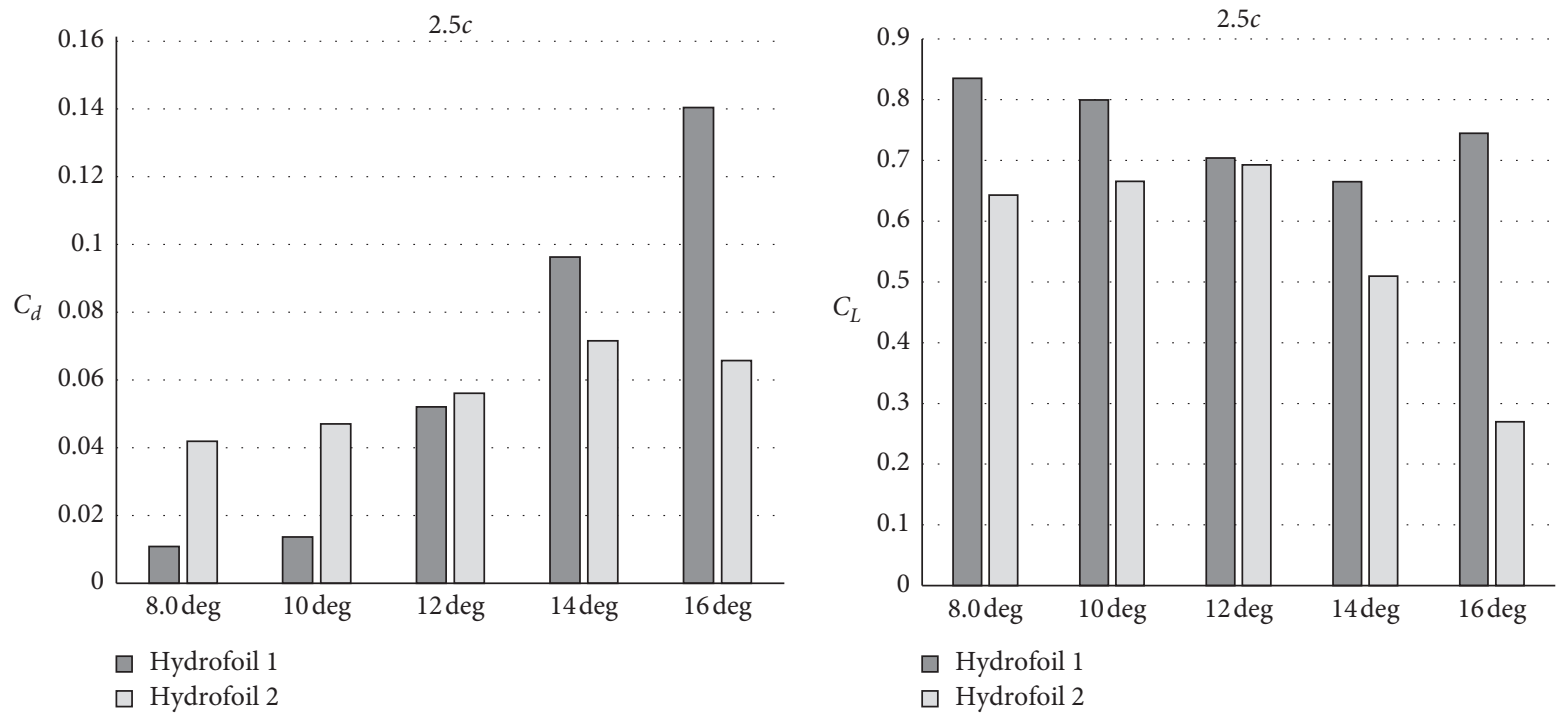

(a)
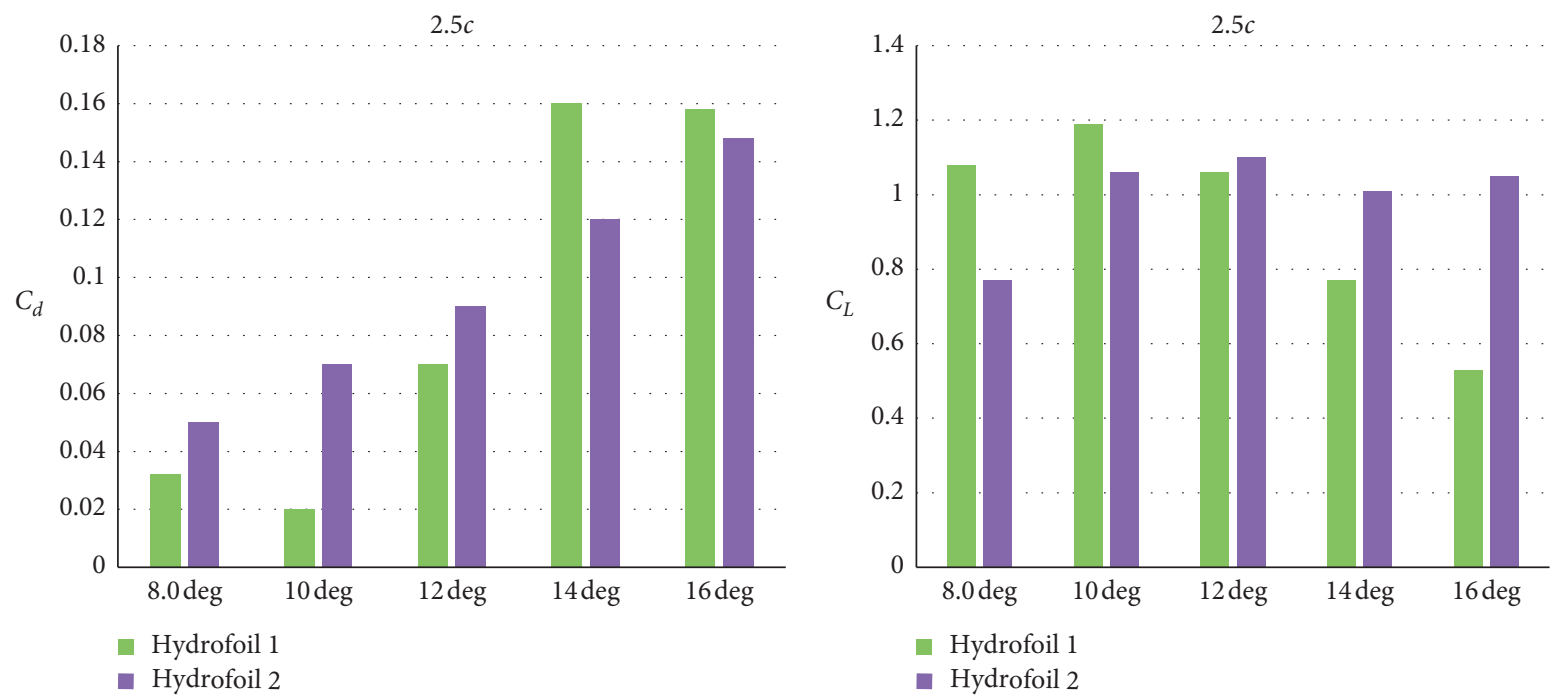

(b)

FIgUre 12: Lift and drag coefficients versus AoA at two conditions $(d=2.5 c)$. (a) Depth $=0.8 c$. (b) W/O FSE. 

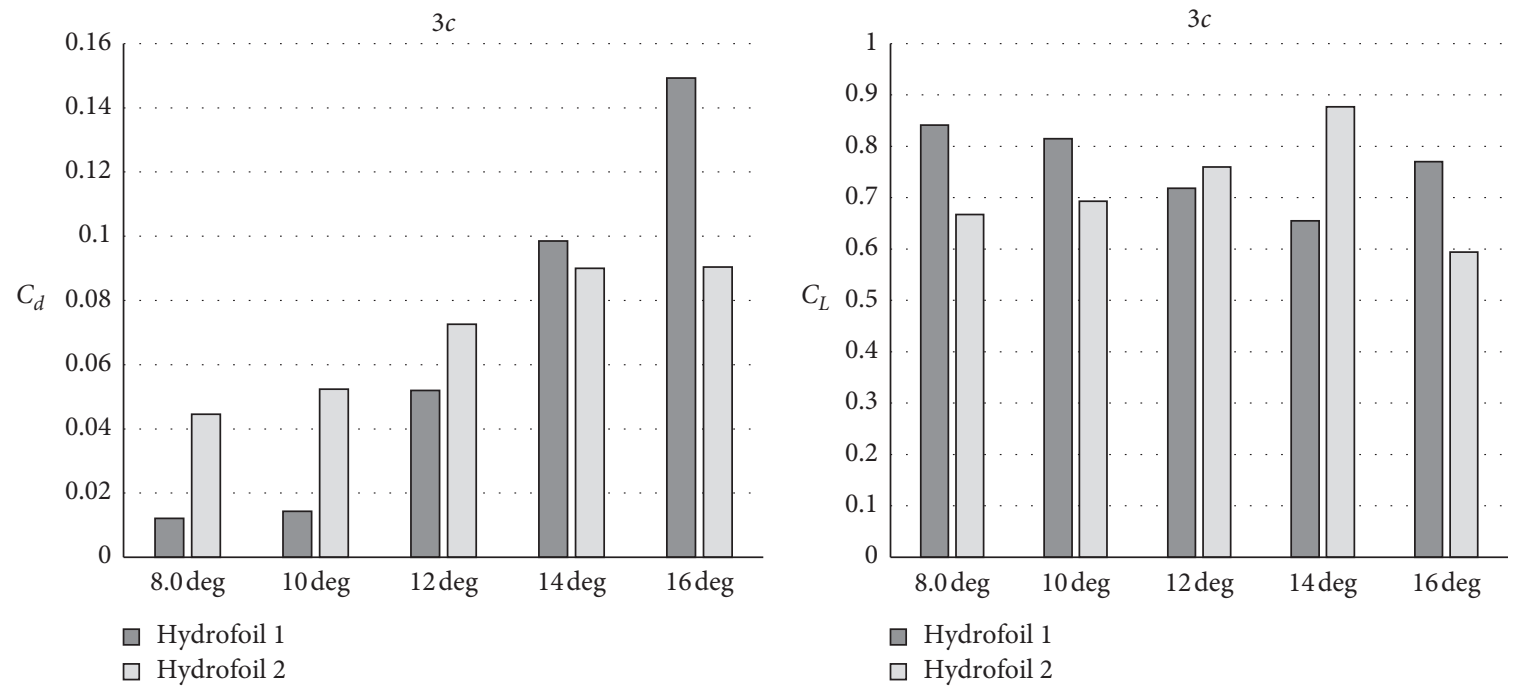

(a)
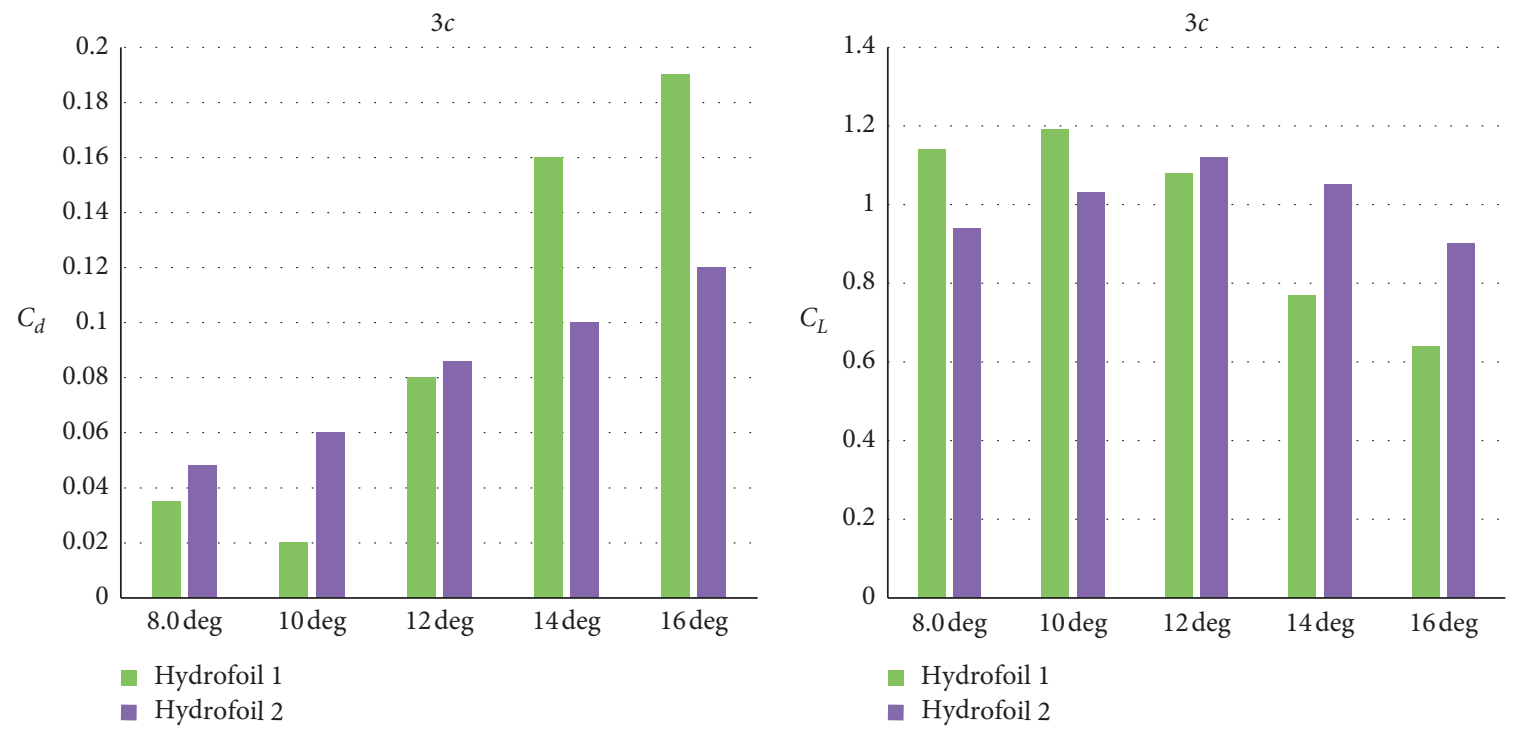

(b)

FIgure 13: Lift and drag coefficients versus AoA at two conditions $(d=3 c)$. (a) Depth $=0.8 c$. (b) W/O FSE.
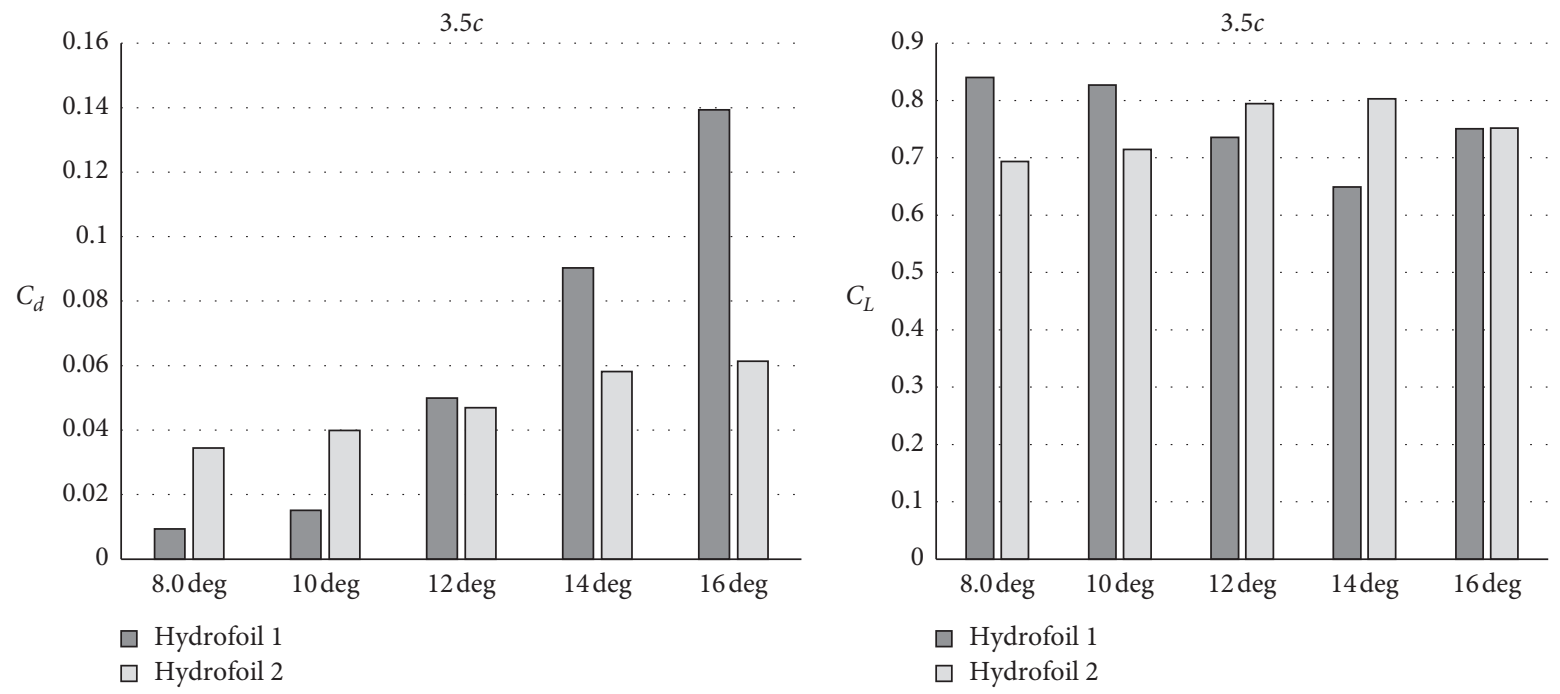

(a)

Figure 14: Continued. 

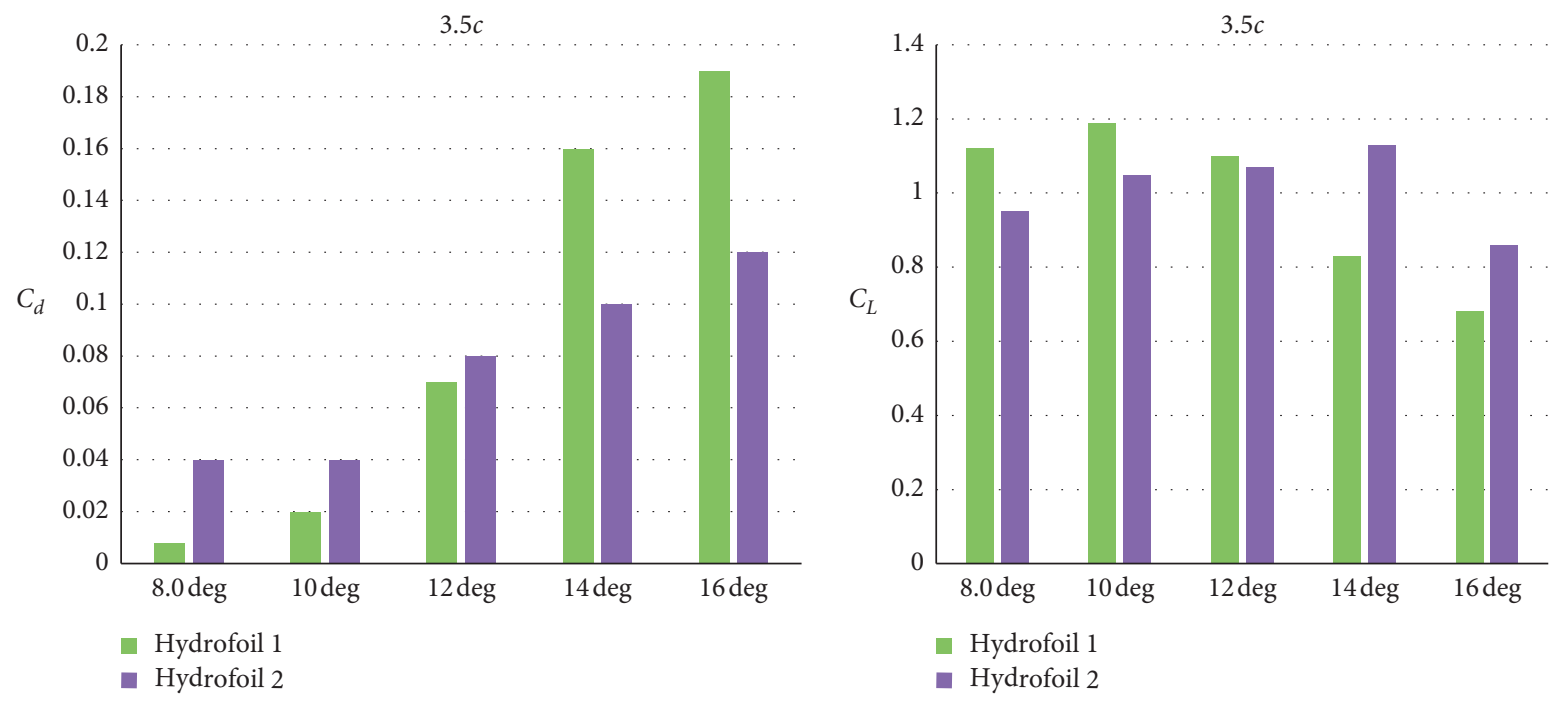

(b)

FIgURe 14: Lift and drag coefficients versus AoA at two conditions $(d=3.5 c)$. (a) Depth $=0.8 c$. (b) W/O FSE.

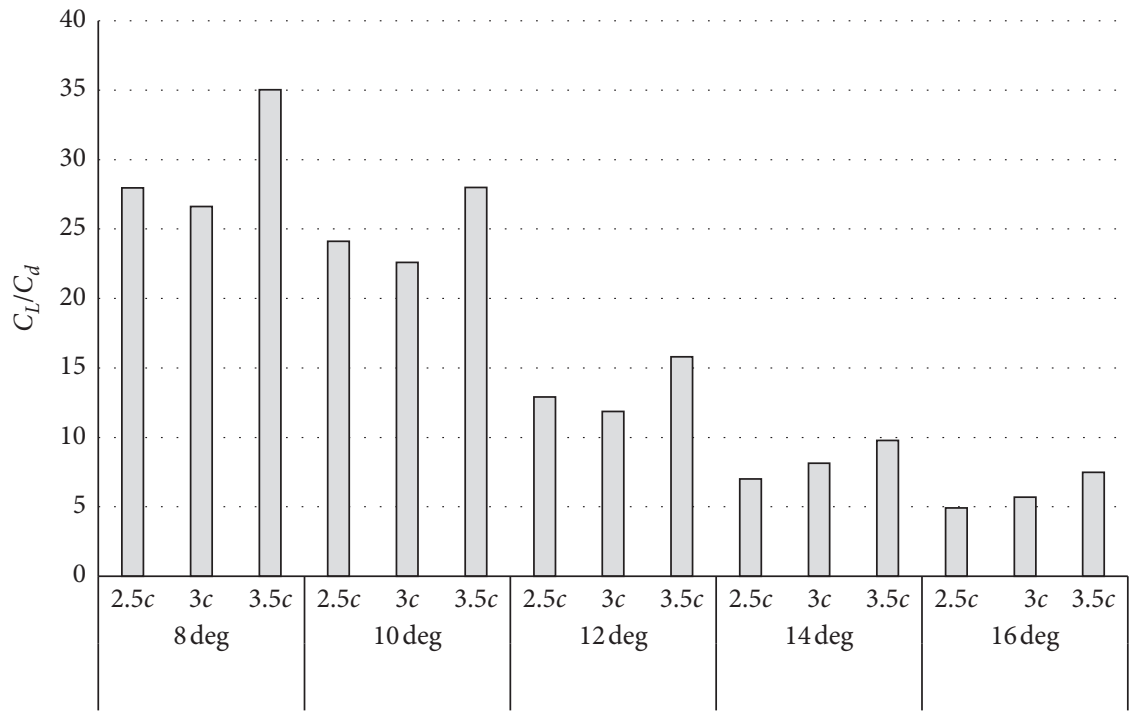

(a)

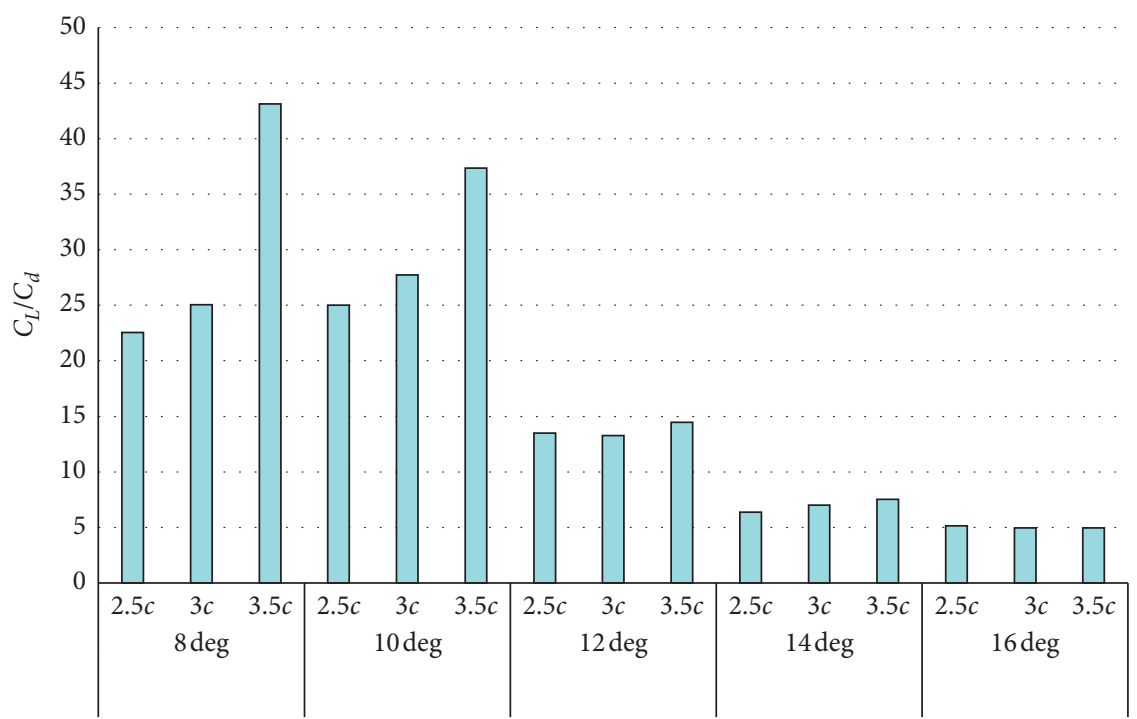

(b)

Figure 15: Total lift-to-drag ratio versus AoA, different distances, and two conditions. (a) Depth $=0.8 c$. (b) W/O FSE. 


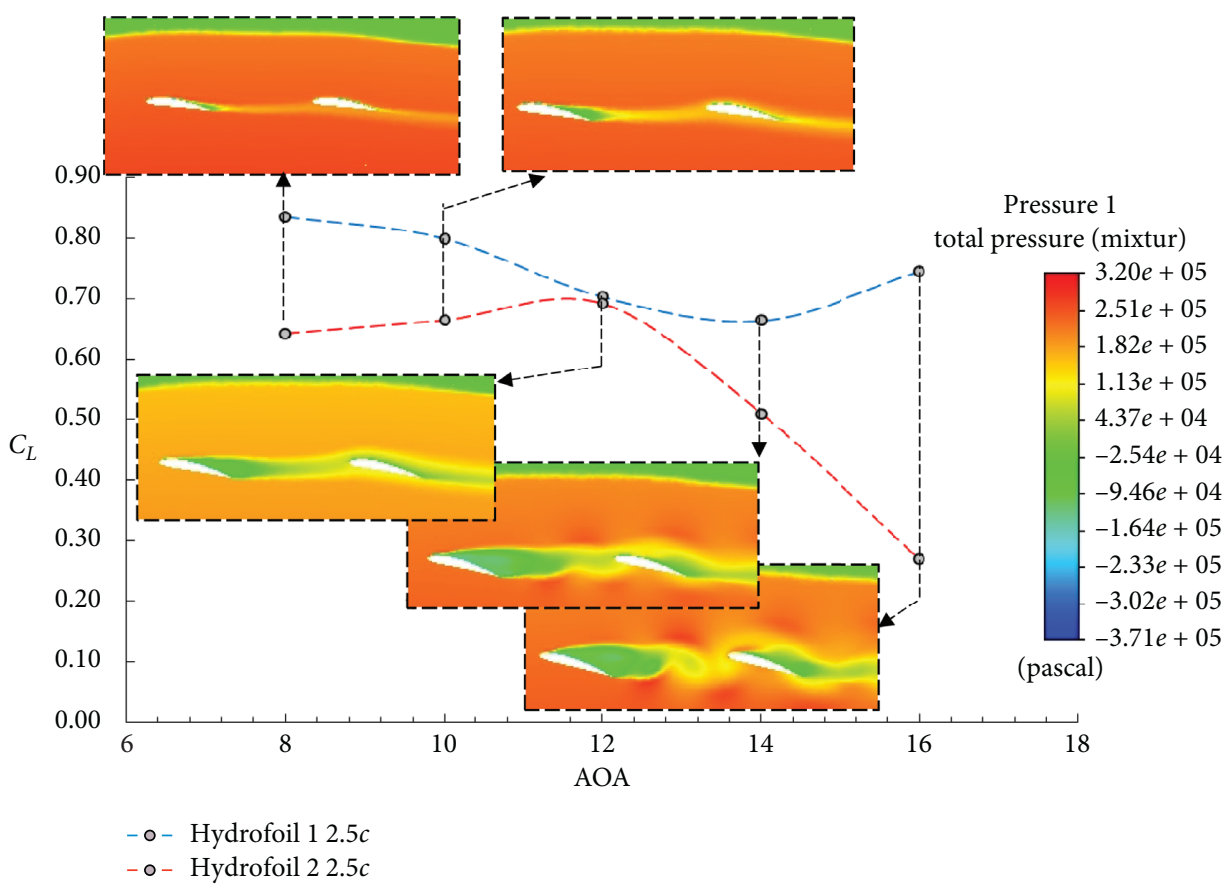

(a)

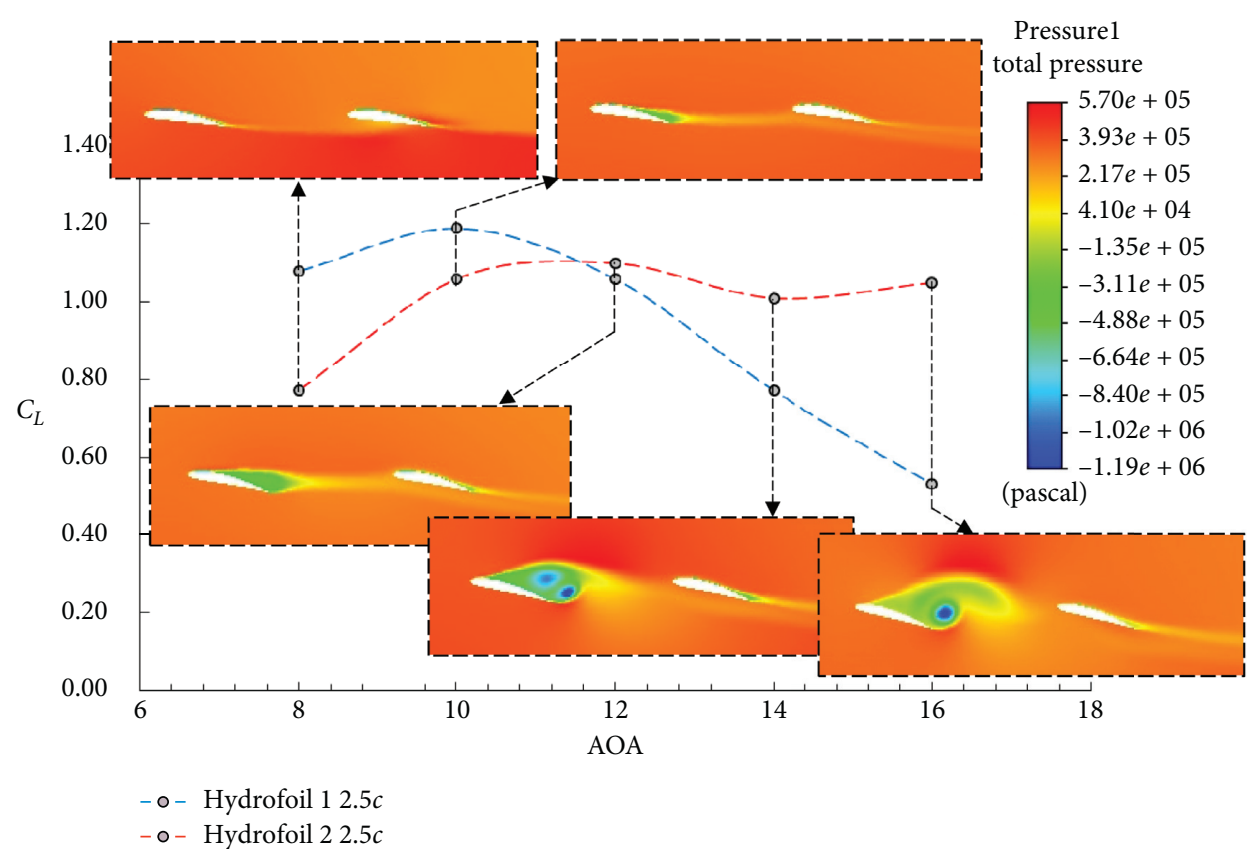

(b)

FIgURE 16: Effect of flow on lift coefficient at two conditions $(d=2.5 c)$. (a) Depth $=0.8 c$. (b) W/O FSE.

Figure 15 shows the total lift-to-drag ratio versus AoA and different distances at velocity $25 \mathrm{~m} / \mathrm{s}$ and depth $0.8 c$ and $\mathrm{W} /$ O FSE.

As shown in Figure 15, at all AoA, the maximum value of the total lift-to-drag ratio is $3.5 \mathrm{c}$ distance; moreover, it can be found that, at all three distances, increasing AoA decreases the total lift-to-drag ratio, and the overall maximum lift-to-drag ratio is observed at $\mathrm{AoA}=8^{\circ}$ and $3.5 c$ distance. The value of the total lift-to-drag ratio has dramatically been reduced at $\mathrm{AoA}=14^{\circ}$ and $16^{\circ}$ by eliminating free surface. Also, this value has become approximately equal for three distances at $\mathrm{AoA}=12^{\circ}$, and the maximum value at $\mathrm{AoA}={ }^{\circ}$ and distance $3.5 \mathrm{c}$ has been increased from 35 to just over 44 .

Figures 16-18 show $C_{L}$ and pressure contours around the hydrofoil 1 and 2 at different AoAs for three different distances and compare results in case of depth $=0.8 \mathrm{c}$ and $\mathrm{W} /$ O FSE. 


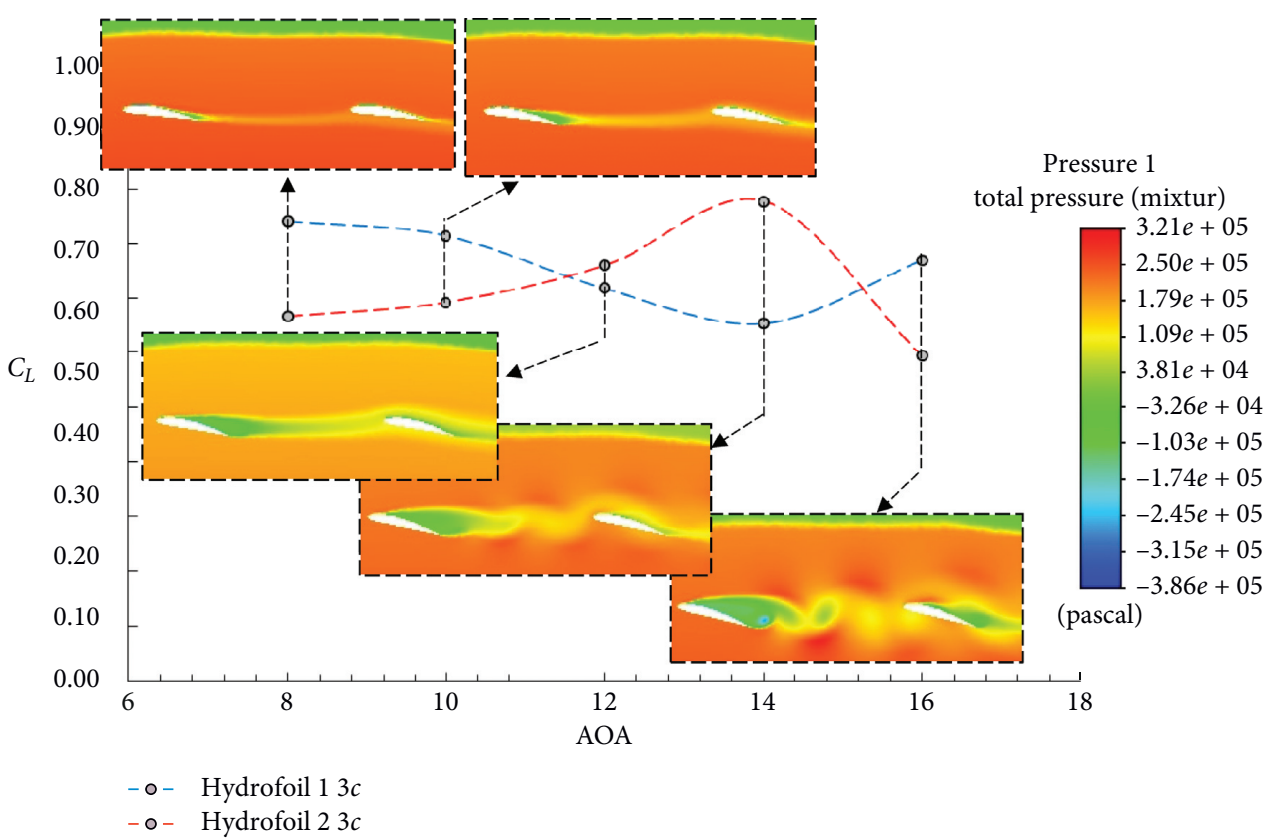

(a)

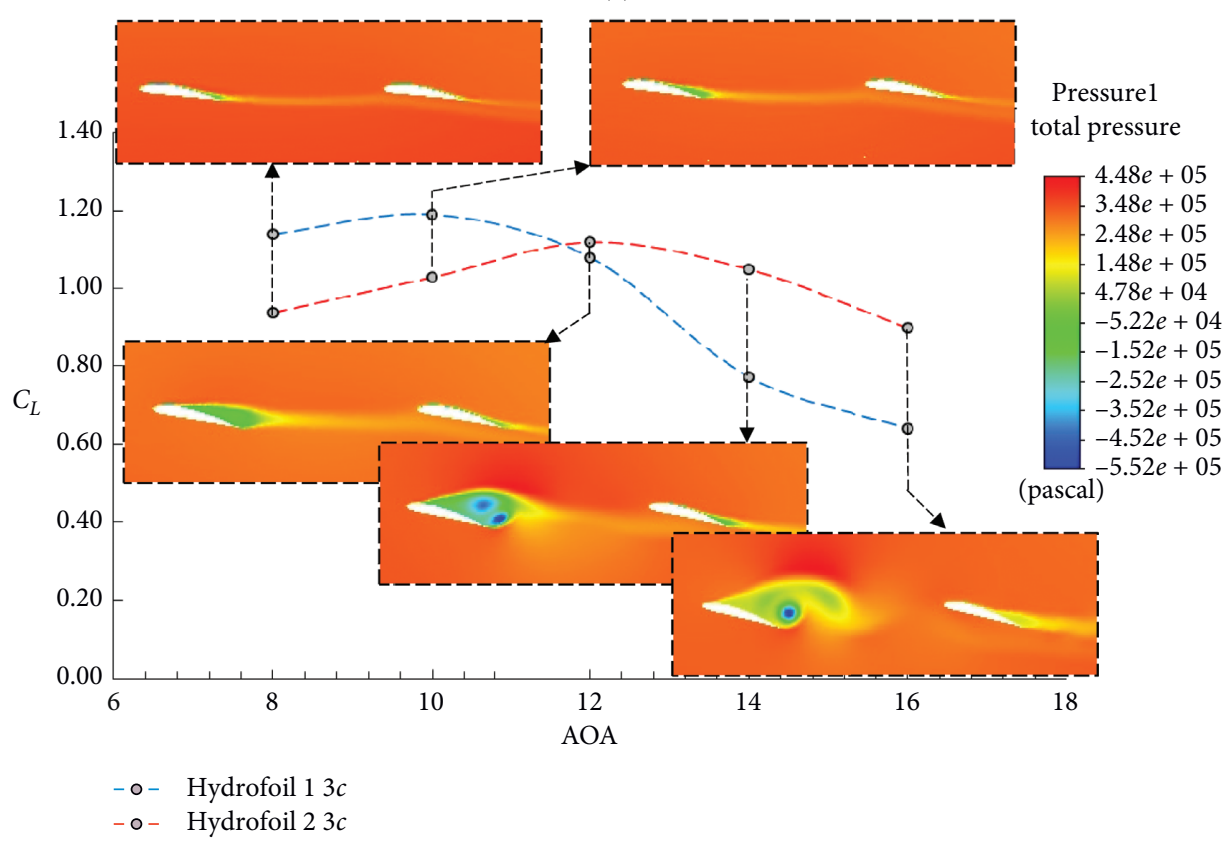

(b)

FIgure 17: The effect of flow on the lift coefficient at two conditions $(d=3 c)$. (a) Depth $=0.8 c$. (b) W/O FSE.

As shown in Figure 16, the low pressure of flow behind the hydrofoil 1 at an angle of attack of $8^{\circ}$ and $10^{\circ}$ reduces the lift coefficient of the hydrofoil 2 . At the $12^{\circ}$ angle of attack, the lift coefficient is reduced due to the increase in the angle of the hydrofoils relative to the flow. However, the low pressure of flow behind hydrofoil 1 has caused a slight increase in the hydrofoil 2 lift coefficient. As the angle of attack increases, the flow behind hydrofoil 1 reduces the pressure at the upper surface of hydrofoil 2 and causes a sharp drop in the lift coefficient. Its effect is also quite evident at a $16^{\circ} \mathrm{AoA}$.
The results show that the free surface elimination in the simulation reverses the trend of $C_{L}$ for both hydrofoils, while both foils' $C_{L}$ is equal at $12^{\circ}$ angle of attack. Also, it causes an increase in total pressure on surface bodies and domain.

Figure 17 shows the effect of the pressure flow behind hydrofoil 1 on the upper and lower surface of hydrofoil 2 at distance $3 c$. At $12^{\circ}$ angle of attack, the low-pressure flow created behind the hydrofoil 1 leads to a decrease in pressure at the upper surface of the hydrofoil 2 and increase in the hydrofoil 2 lift coefficient. In the case of the $14^{\circ} \mathrm{AoA}$, it can be concluded that, despite the increase in the angle of attack 


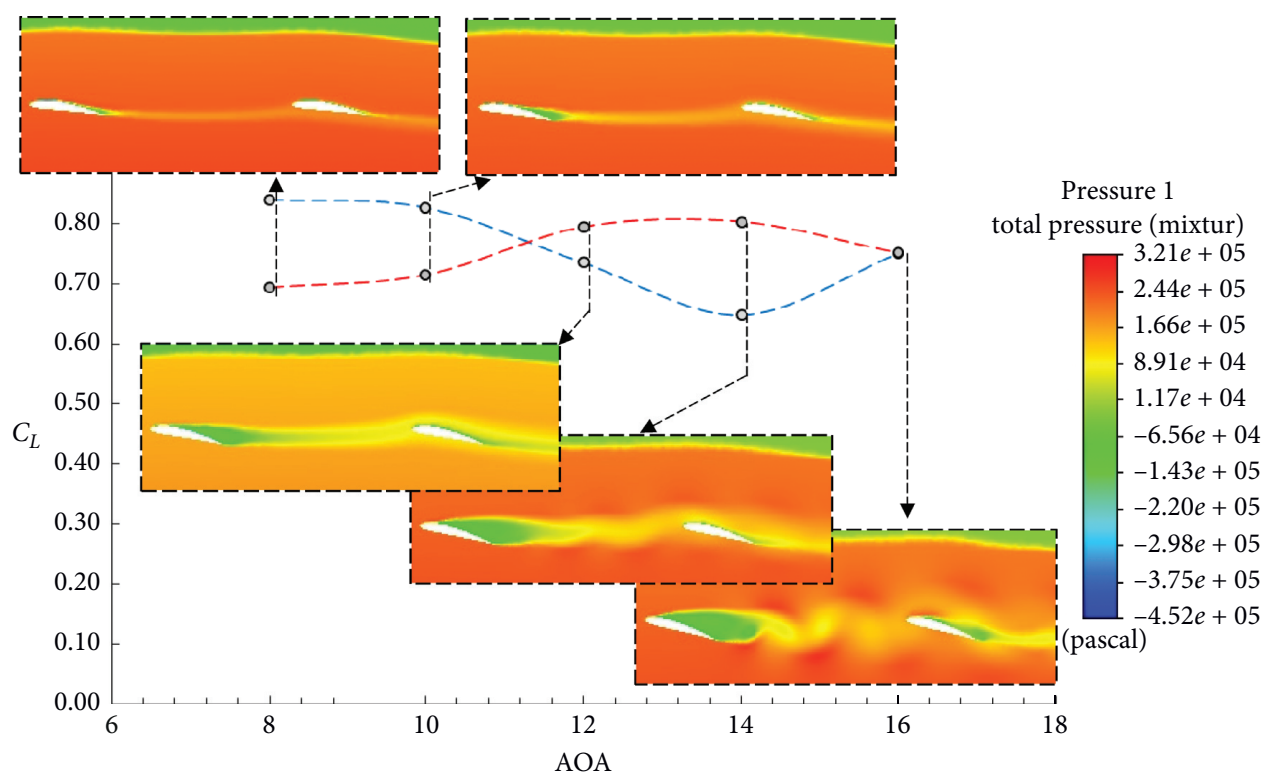

- o- Hydrofoil $13.5 c$

- o- Hydrofoil $23.5 c$

(a)

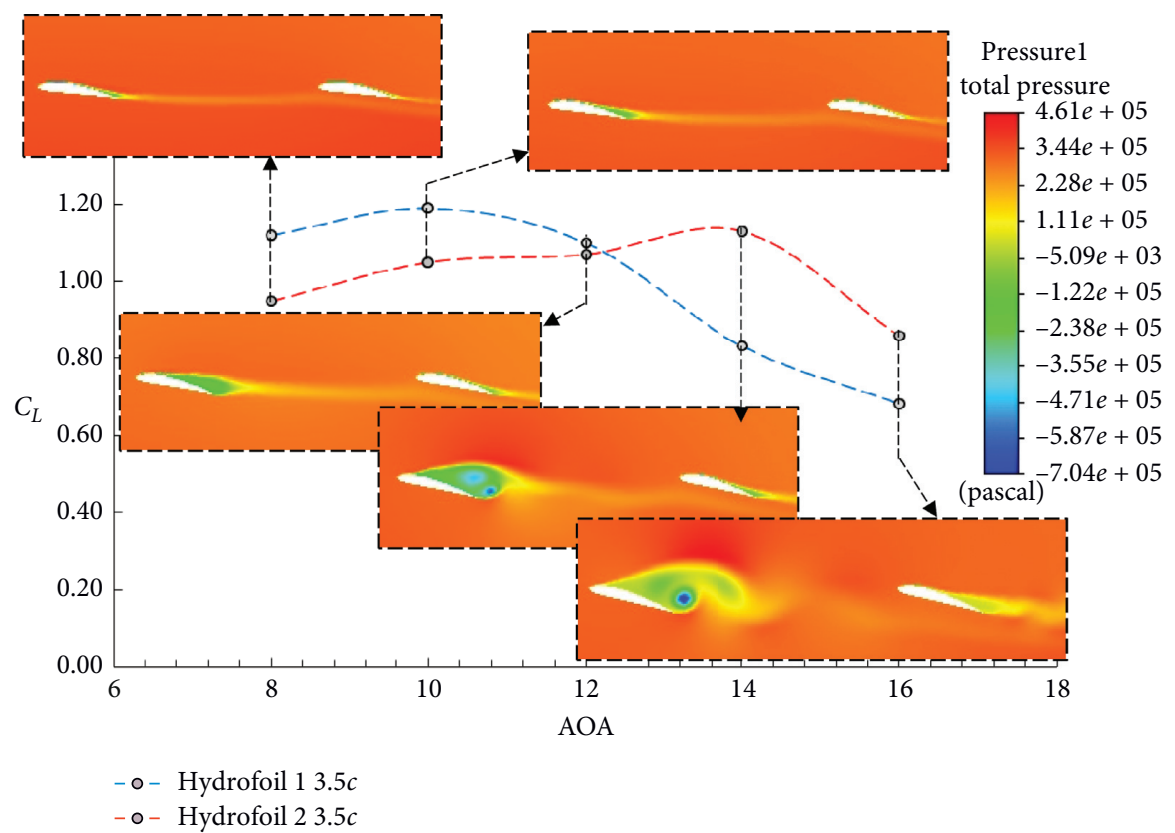

(b)

FIgURE 18: Effect of flow on lift coefficient at two conditions $(d=3.5 c)$. (a) Depth $=0.8 c$. (b) W/O FSE.

and the decrease in the lift force vector, the effect of the lowpressure flow caused by hydrofoil 1 on the upper surface of hydrofoil 2 leads to a rise in the lift force. However, at the $16^{\circ}$ angle of attack, the low-pressure flow created by hydrofoil 1 hits the lower surface of hydrofoil 2; thus, a downward force is generated, which ultimately leads to a reduction in the lift force. Part (b) of Figure 17 reveals that elimination of free surface leads to an increase in $C_{L}$ of the hydrofoil 2 and decrease on hydrofoil 1 at the $16^{\circ}$ angle of attack. Also, separation has occurred on hydrofoil 1 with high intensity.
As shown in Figure 18, increasing the angle of attack leads to increasing lift coefficient, but due to increasing wave height generated by hydrofoil 1 , the lift coefficient remains constant in $10^{\circ}$, and then, the static stall will occur and the lift coefficient begins to decrease. As the angle of attack increases further, a dynamic stall occurs and the lifting coefficient increases. It can also be seen that due to the larger distance between the two hydrofoils at the $16^{\circ}$ angle of attack, the effect of the pressure flow behind the hydrofoil 1 on the hydrofoil 2 is almost negligible. However, at an angle of $14^{\circ}$, 


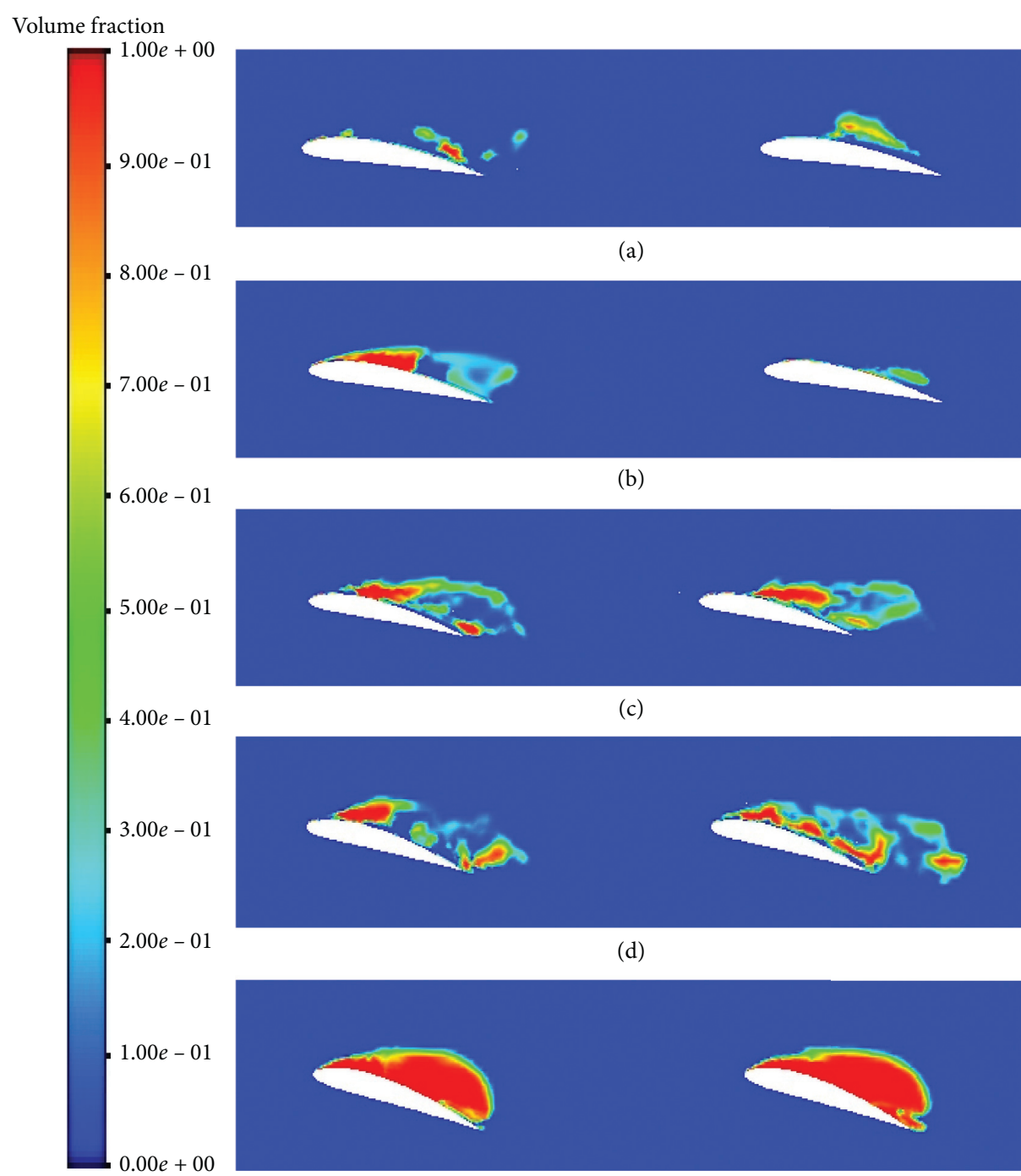

(e)

Figure 19: Distributions of cavity shape at different AoAs. (a) AoA $=8^{\circ}$. (b) AoA $=10^{\circ}$. (c) AoA $=12^{\circ}$. (d) AoA $=14^{\circ}$. (e) AoA $=16^{\circ}$.

the low-pressure flow created behind hydrofoil 1 leads to a decrease in pressure and the upper surface of hydrofoil 2 leads to an increase in the lift coefficient of hydrofoil 2 compared to hydrofoil 1. Part (b) of Figure 18 shows that, in the second case, due to the without-free surface condition, pressure on trailing edge had been dramatically reduced, so separation has occurred on the upper surface. This issue leads to reduce in $C_{L}$ on hydrofoil 1 .

In the last part of the present study, the investigation of supercavitation on the surface body has been performed by the Zwart cavitation model according to Kubota et al. [14]. This study has been conducted at $\sigma=0.34$, depth $0.8 \mathrm{~m}$, and distance $2.5 c$. Moreover, the effect of AoA has been studied on this phenomenon.

Figure 19 displays that supercavitation has occurred at $\sigma=0.34$ since the pressure on the top surface had reduced. Also, it has been developed on the hydrofoil 2 more than the hydrofoil 1 due to the existence of hydrofoil 1 . Thus, hydrofoil 1 leads to formation of turbulence of flow front hydrofoil 2. As a result of this turbulence, pressure on the leading age of hydrofoil 2 decreased more.
Besides, a comparison of the supercavitation at different AoAs shows an increase in this factor which finally leads to development of supercavitation on the upper surface body. The value of $\mathrm{Cp}_{\min }$ has a fundamental role in the supercavitation occurrence and depends on AoA. This means that the increase of AoA causes cavitation.

\section{Conclusion}

In this paper, Reynolds-averaged Navier-Stokes (RANS) with the shear stress transport (SST) $K-\omega$ turbulent model is used to analyze the effect of the submergence depths on the lift and drag coefficients of the tandem hydrofoils with NACA4412 profiles in a two-phase flow domain. Furthermore, the Zwart cavitation model has been introduced for analyzing cavitation and to study the influence of AoA on this phenomenon. Also, the effects of different distances in the various angles of attack (AoA) were investigated. Flow velocity is $25 \mathrm{~m} / \mathrm{s}$ in all cases. For different depths' case study, the tandem hydrofoils' distance is considered to be $3.5 c$ and AoA is $10^{\circ}$ for both hydrofoil 1 and 2 . Five different 
submergence depths are considered in the range of 0.6 to $1.2 c$ with a $0.2 c$ increment as well as W/O FSE.

The most important results of the conclusion section can be addressed as

(i) By increasing depth, the drag coefficient increases for both hydrofoils 1 and 2 as well as the lift coefficient.

(ii) The drag coefficient of hydrofoil 2 is bigger than its value for hydrofoil 1 in all depths.

(iii) The difference between the lift coefficient for hydrofoils 1 and 2 is smaller than the drag coefficient.

(iv) Moreover, $C_{L}$ for hydrofoil 1 is bigger than hydrofoil 2, while $C_{d}$ is vice versa.

(v) In the case of W/O FSE, $C_{d}$ of hydrofoil 2 decreases, while for hydrofoil $1, C_{d}$ increases.

(vi) Free surface elimination leads to reduced effect of distance between hydrofoils on the total lift-todrag ratio, at AoA over $10^{\circ}$.

(vii) Free surface elimination leads to an increase in the range of pressure changes on the model surface. As a result of these changes, separation begins at smaller AoA.

(viii) As a result of turbulent flow generation by the wave on the free surface, the dynamic stall angle is obtained for hydrofoil 1.

(ix) The increase in AoA leads to a growth in supercavitation.

(x) Supercavitation on hydrofoil 2's surface is more developed.

In order to observe the effect of the tandem hydrofoil distance on the hydrodynamic responses of NACA 4412, three case studies are investigated. Each case study includes 5 different AoAs from ${ }^{\circ}$ to $16^{\circ}$. The numerical results show that the AoA increment leads to an increase in the free surface height on both hydrofoils 1 and 2, while the free surface height decreases in the downstream. The value of the hydrofoil 2 lift coefficient strongly depends on the lowpressure flow created behind hydrofoil 1 so that the angle of attack and the distance between the two hydrofoils affect the upper and lower surface pressure distribution of the hydrofoil 2, which changes the lift coefficient of hydrofoil 2. At small attack angles, i.e., ${ }^{\circ}$ and $10^{\circ}$, the pressure of hydrofoil 1 has a very little effect on hydrofoil 2 , while at an angle of $12^{\circ}$, the pressure flow affects the upper surface of the hydrofoil 2 and increases the lift coefficient in all three distances. In the AoA $=14^{\circ}$, due to flow separation and the effect of the lowpressure flow on the upper surface of the hydrofoil 2, the lift coefficient is reduced, while in the attack angle of $16^{\circ}$, only the separation of the flow causes the lift coefficient to decrease. The lift coefficient of hydrofoil 1 at depth $=0.8 c$ and AoA $=16^{\circ}$ is higher than hydrofoil 2, while in the W/O FSE simulation, the result is inverse. The results show that the pressure on the body surface has been led to an increase by the elimination of the free surface; therefore, lift coefficient and drag coefficient have been increased. According to the results, the difference in the value of results between single phase and two phase is considerable, so bodies should be investigated in a two-phase flow domain. Moreover, hydrofoil 1 had led to the turbulence of flow behind hydrofoil 2 ; hence, the minimum pressure coefficient on the surface has been reduced. As a result, supercavitation on hydrofoil 2's surface is more evolved [15-19].

\section{Data Availability}

No data were used to support the findings of the study.

\section{Conflicts of Interest}

The authors declare that they have no conflicts of interest.

\section{References}

[1] A. Sharma, M. S. Sarwara, H. Singh, L. Swarup, and R. K. Sharma, "CFD and real time analysis of a symmetric airfoil," International Journal of Research in Aeronautical and Mechanical Engineering, vol. 2, no. 7, pp. 84-93, 2014.

[2] J. Liu and R. G. Hekkenberg, "Hydrodynamic characteristics of twin-rudders at small attack angles," in IMDC 2015: Proceedings of the 12th International Marine Design Conference, pp. 11-14, Tokyo, Japan, May 2015.

[3] M. A. F. Kandil and A. O. Elnady, "CFD analysis of GOE 387airfoil," IOSR Journal of Mechanical and Civil Engineering (IOSR-JMCE), vol. 14, no. 5, pp. 80-85, 2017.

[4] H. Mehdi, S. Gaurav, and M. Sharma, "Numerical investigation of fluid flow and aerodynamic performance on a $2 \mathrm{D}$ NACA-4412 airfoil," International Journal of Research in Engineering and Innovation, vol. 1, no. 1, 5 pages, 2016.

[5] S. Adjali, O. Imine, M. Aounallah, and M. Belkadi, "Numerical simulation of free surface water wave for the flow around NACA 0012 hydrofoil and wigley hull using VOF method," International Journal of Mechanical and Mechatronics Engineering, vol. 9, no. 5, pp. 884-888, 2015.

[6] G. H. Shahariar, M. R. Hasan, and M. Mashud, "Laminar boundary layer flow separation control at the leading edge of an airfoil," in International Conference on Mechanical, Industrial and Energy Engineering, Khulna, Bangladesh, December 2014.

[7] D. Udaya Kumar and S. Kannan, "Aerodynamic analysis of multi element airfoil," Journal of Aeronautics \& Aerospace Engineering, vol. 5, no. 2, 2016.

[8] H. Sogukpinar, "Numerical simulation of 4-digit inclined NACA 00xx airfoils to find optimum angle of attack for airplane wing," Uludag University Journal of The Faculty of Engineering, vol. 22, no. 1, pp. 169-178, 2017.

[9] M. I. Uddin and M. M. Karim, "Application of volume of fluid (VOF) method for prediction of wave generated by flow around cambered hydrofoil," Procedia Engineering, vol. 194, pp. 82-89, 2017.

[10] F. Menter and C. Rumsey, "Assessment of two-equation turbulence models for transonic flows," in 25th Fluid Dynamics Conference, p. 2343, Colorado Springs, CO, USA, June 1994.

[11] C. W. Hirt and B. D. Nichols, "Volume of fluid (VOF) method for the dynamics of free boundaries," Journal of Computational Physics, vol. 39, no. 1, pp. 201-225, 1981.

[12] A. J. Wadcock, "Investigation of low-speed turbulent separated flow around airfoils NASA-CR-177450," 1987. 
[13] J. H. Duncan, "The breaking and non-breaking wave resistance of a two-dimensional hydrofoil," Journal of Fluid Mechanics, vol. 126, pp. 507-520, 1983.

[14] A. Kubota, H. Kato, and H. Yamaguchi, "A new modelling of cavitating flows: a numerical study of unsteady cavitation on a hydrofoil section," Journal of Fluid Mechanics, vol. 240, no. 1, pp. 59-96, 1992.

[15] Dark roasted blend, "The history of hydrofoils dark roasted blend," https://www.darkroastedblend.com/2012/07/historyof-hydrofoils.html.

[16] Y. D. Dwivedi, M. S. Prasad, and S. Dwivedi, "Experimental aerodynamic static stability analysis of different wing planforms," International Journal of Advancements in Research \& Technology, vol. 2, no. 6, pp. 60-63, 2013.

[17] E. Esmaeilifar, M. Hassan Djavareshkian, B. Forouzi Feshalami, and A. Esmaeili, "Hydrodynamic simulation of an oscillating hydrofoil near free surface in critical unsteady parameter," Ocean Engineering, vol. 141, pp. 227-236, 2017.

[18] T. Putranto and A. Sulisetyono, "Lift-drag coefficient and form factor Analyses of hydrofoil due to the shape and angle of attack," International Journal of Applied Engineering Research, vol. 12, no. 21, pp. 11152-11156, 2017.

[19] USS high point: The navy's first hydrofoil patrol craft, "Naval history blog," 2012, https://www.navalhistory.org/2012/08/17/ uss-high-point-the-navys-first-hydrofoil-patrol-craft. 